\title{
Neural Deletion of Glucose Transporter Isoform 3 Creates Distinct Postnatal and Adult Neurobehavioral Phenotypes
}

\author{
๑Bo-Chul Shin, ${ }^{1}$ CCarlos Cepeda, ${ }^{2}{ }^{\circledR}$ Ana María Estrada-Sánchez, ${ }^{2}{ }^{\circledR}$ Michael S. Levine, ${ }^{2}$ Laya Hodaei, ${ }^{1}$ Yun Dai, ${ }^{1}$ \\ Jai Jung, ${ }^{1}$ Amit Ganguly, ${ }^{1}$ ○Peter Clark, ${ }^{3}$ and ${ }^{\circledR}$ Sherin U. Devaskar ${ }^{1}$ \\ ${ }^{1}$ Department of Pediatrics, Division of Neonatology and Developmental Biology and Neonatal Research Center at the UCLA Children's Discovery and \\ Innovation Institute, ${ }^{2}$ Intellectual and Developmental Disabilities Research Center and Brain Research Institute, and ${ }^{3}$ Department of Molecular and Medical \\ Pharmacology and Crump Institute for Molecular Imaging, David Geffen School of Medicine, University of California, Los Angeles, California 90095
}

We created a neural-specific conditional murine glut $3(\operatorname{Slc} 2 \mathrm{A3})$ deletion $\left(\mathrm{glut}^{\mathrm{flox} / \mathrm{flox} / \mathrm{nestin}-\mathrm{Cre}+}\right)$ to examine the effect of a lack of Glut 3 on neurodevelopment. Compared with age-matched $g l u t 3^{\text {flox/flox }}=$ WT and heterozygotes $\left(\right.$ glut $3^{\text {flox } /+/ \text { nestin-Cre+ }+}$ ), we found that a $>90 \%$ reduction in male and female brain Glut3 occurred by postnatal day 15 (PN15) in glut $3^{\text {flox/flox/nestin -Cre+ }}$. This genetic manipulation caused a diminution in brain weight and cortical thickness at PN15, a reduced number of dendritic spines, and fewer ultrasonic vocalizations. Patch-clamp recordings of cortical pyramidal neurons revealed increased frequency of bicuculline-induced paroxysmal discharges as well as reduced latency, attesting to a functional synaptic and cortical hyperexcitability. Concomitant stunting with lower glucose concentrations despite increased milk intake shortened the lifespan, failing rescue by a ketogenic diet. This led to creating glut $3^{\text {flox/flox/CaMK } 2 \alpha \text {-Cre }+}$ mice lacking Glut3 in the adult male limbic system. These mice had normal lifespan, displayed reduced IPSCs in cortical pyramidal neurons, less anxiety/fear, and lowered spatial memory and motor abilities but heightened exploratory and social responses. These distinct postnatal and adult phenotypes, based upon whether glut 3 gene is globally or restrictively absent, have implications for humans who carry copy number variations and present with neurodevelopmental disorders.

Key words: dendrite spine; microcephaly; neuroexcitation; postnatal stunting; shortened lifespan; sociability

Significance Statement

Lack of the key brain-specific glucose transporter 3 gene found in neurons during early postnatal life results in significant stunting, a reduction in dendritic spines found on neuronal processes and brain size, heightened neuronal excitability, along with a shortened lifespan. When occurring in the adult and limited to the limbic system alone, lack of this gene in neurons reduces the fear of spatial exploration and socialization but does not affect the lifespan. These features are distinct heralding differences between postnatal and adult phenotypes based upon whether the same gene is globally or restrictively lacking. These findings have implications for humans who carry copy number variations pertinent to this gene and have been described to present with neurodevelopmental disorders.

\section{Introduction}

Glucose transporter isoform 3 (GLUT3), with the highest affinity for glucose, mediates glucose transport to fuel cellular oxidative

Received Feb. 5, 2018; revised Sept. 6, 2018; accepted Sept. 8, 2018.

Author contributions: B.-C.S., M.S.L., and S.U.D. edited the paper; S.U.D. wrote the first draft of the paper. S.U.D. designed research; B.-C.S., C.C., A.M.E.-S., L.H., Y.D., J.J., A.G., P.C., and S.U.D. performed research; S.U.D. contributed unpublished reagents/analytic tools; B.-C.S., C.C., A.M.E.-S., M.S.L., L.H., A.G., P.C., and S.U.D. analyzed data; B.-C.S., C.C., P.C., and S.U.D. wrote the paper.

This work was supported by the National Institutes of Health (Grants HD-81206 and HD-41230 to S.U.D.). The Cell, Circuits and Systems Analysis Core is also supported by the NIH (Grant U54HD087101 to M.S.L.). We thank Monica Sondhi, Hyeri Park, Erin Clagett, and Kyung Keun Chee for assistance in mouse genotyping and brain sectioning and Jesse D. Cushman in the UCLA Animal Neurobehavioral Core and Kym Francis Faull at the UCLA Semel Institute for Neuroscience and Human Behavior for help with liquid chromatography/tandem mass spectrometry.

The authors declare no competing financial interests. metabolism. It belongs to a family of membrane-spanning glycoproteins called the facilitative glucose transporters (GLUT1-14) and is expressed in the highly metabolic neurons of adult brain, next in male testicular spermatids, and in lesser amounts within placental trophoblasts (Devaskar et al., 1992; Nagamatsu et al., 1992; Gould and Holman, 1993; Shin et al., 1997; Ganguly et al., 2007; Galardo et al., 2008; Zhao et al., 2010; Alves et al., 2014).

Given the critical role of glucose transport, enhanced GLUT3 expression has been seen in various cancers (Flavahan et al., 2013;

Correspondence should be addressed to: Sherin U. Devaskar, David Geffen School of Medicine, University of California, 10833 Le Conte Avenue, MDCC-22-402, Los Angeles, CA 90095. E-mail: sdevaskar@mednet.ucla.edu. https://doi.org/10.1523/JNEUROSCI.0503-18.2018

Copyright $\odot 2018$ the authors $\quad 0270-6474 / 18 / 389579-21 \$ 15.00 / 0$ 
A

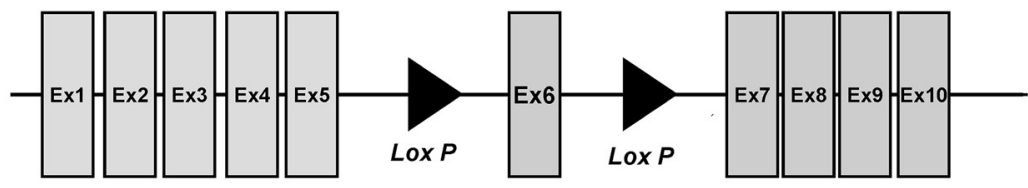

B

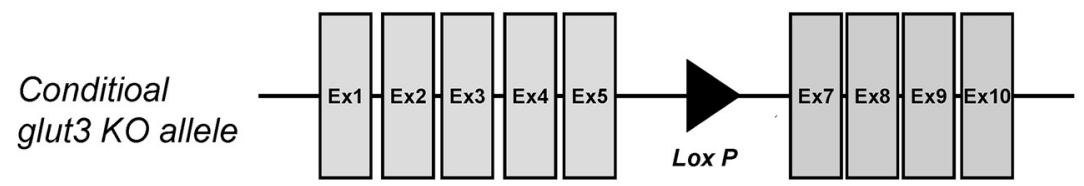

$100 \mathrm{bp}$

C

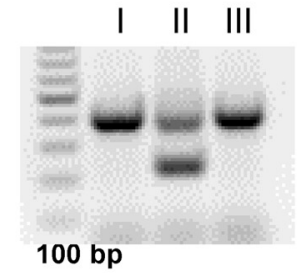

$-$

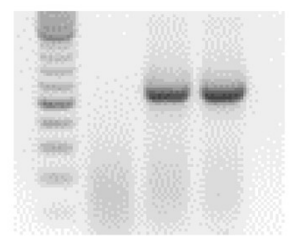

Top: genotypes

I, CON (flox/ flox, 402bp)

II, HT (233bp \& 402bp); III, KO (402bp)

Bottom: cre expression (554bp)
D Nestin-cre

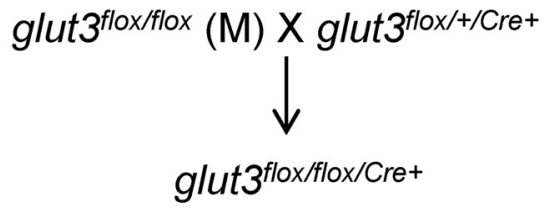

$(F)$

E CamK2a-cre

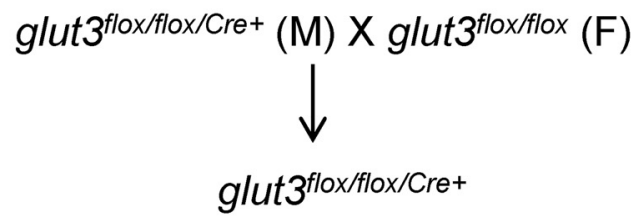

Figure 1. Targeted conditional mouse glut3 gene construct and genotyping strategy. A, B, Schematic representation of the conditional glut3 (S/c2a3) K0 targeting vector with two LoxP sites designed for the deletion of Exon 6. C, PCR analysis of mouse tail genomic DNA samples showing the presence of glut $3^{\text {flox/flox }}(+/+; 402 \mathrm{bp}, \mathrm{CON})$, glut $3^{\text {flox } /+/ \mathrm{re}+}+(+/-; 233 \mathrm{bp}$ and $402 \mathrm{bp}$ with cre expression, $\mathrm{HT})$ and $g /$ lut $\mathrm{f}^{\text {flox/flox/Cre+ }}(-/-; 402$ bp with cre expression seen as a 554 bp DNA fragment, KO). Bottom, cre expression with a 554 bp DNA fragment. $D$, Scheme of breeding for the glut $3^{\text {flox/flox }}$ with nestin-Cre and $\boldsymbol{E}$, Camk2 $\alpha$-Cre mice.

Masin et al., 2014; Onodera et al., 2014; Agostini et al., 2016; Barron et al., 2016; Massari et al., 2016) and under hypoxic conditions (Bruckner et al., 1999; Zovein et al., 2004; Yu et al., 2008; Fung et al., 2010). Conversely, a reduction in GLUT3 expression is a hallmark of Alzheimer's disease (Shah et al., 2012; Szablewski, 2017). Gene (Slc2A3) copy number variations (CNVs) have been associated with delaying the age of onset of Huntington's disease (Vittori et al., 2014) and protection against rheumatoid arthritis (Veal et al., 2014). During infancy and childhood, such CNVs have been associated with increased incidence of meningomyeloceles in offspring of diabetic mothers (Connealy et al., 2014) and in infants with the 22q deletion syndrome, many of whom have neurocognitive deficits (Dworschak et al., 2015). Reduced transactivation of GLUT3 related to other gene CNVs has also been associated with dyslexia (Roeske et al., 2011). In fact, aberrant trans-regulation of GLUT3 was associated with perturbed functional frontoparietal connectivity (Skeide et al., 2015). Conversely, duplication of the gene was associated with attention deficit hyperactivity disorder (ADHD) (Lesch et al., 2011) in children with a carbohydrate craving or with neurocognitive deficits observed in adults contributing to the ADHD risk (Merker et al., 2017). Therefore, the clinical presentations of Slc2A3 CNVs differ in infancy compared with the adult.

Given these emerging associations of glut3 gene variations with human disease conditions, we previously examined the role of this critical gene during early development. To this end, we performed classical murine glut3 deletion and observed that complete loss of Glut3 as encountered in homozygotes led to early embryonic (E7.5) demise. This was related to the lack of Glut3 in the trophectoderm, which is essential for fueling the developing embryo (Ganguly et al., 2007). Our initial observation was substantiated by another group as well (Schmidt et al., 2009). A similar scenario emerged when antisense glut3 morpholinos were used in Danio rerio embryos, culminating in early embryonic growth restriction and ultimate demise (Carayannopoulos et al., 2014). In contrast, the heterozygous glut3-null mice demonstrated a mild slowing of late gestation fetal growth, only to recover postnatally with survival and successful procreation (Ganguly et al., 2007). This slowing of fetal growth was secondary to reduced maternal to fetal glucose transport mediated by the 
diminished placental Glut3 (Ganguly et al., 2012). However, the heterozygotes appeared phenotypically normal during the postnatal phase, presenting as adults with certain neurobehavioral aberrations that mimicked autism spectrum disorders (Zhao et al., 2010). Further, clinical seizures could be triggered by subjecting heterozygotes to hypoxic ischemia or pentylenetetrazole administration (Fung et al., 2010). These results instigated our questioning of whether the brain-related changes were primarily due to neural glut3 deficiency, secondary to placental glut3 deficiency, or both. To this end, we created a conditional murine neural specific glut3 deletion, which for the first time demonstrated the homozygote's postnatal survival but with a shortened lifespan. This precluded characterization of the adult phenotype. However, when glut3 deletion was engineered to be spatially limited to the limbic system, the mice had normal lifespans and demonstrated adverse effects on synaptic activity and neurobehavioral responses in the adult.

\section{Materials and Methods}

\section{Creation and genotyping of glut $3^{\text {flox/flox/Cre+ }}$ mice}

Glut $3^{\text {flox/flox/nestin-Cre+ }}$ and glut $3^{\text {flox/flox/CaMK2 } \alpha-C r e+}$ mouse lines: Glut $3^{\text {flox/+ }}$ mice were generated on C57BL/6 background by inserting LoxP sites into intron 5 and 6 (Mouse Biology Program, University of California, Davis). We crossed male glut $3^{\text {lox/+ }}$ mice with female glut $3^{\text {flox/+ }}$ mice, generating glut ${ }^{\text {flox/flox }}$ mice. For generation of glut $^{\text {flox/flox/Cre+ }}$ by Cre/loxP recombination, we next crossed glut $3^{\text {flox/flox }}$ mice with transgenic mice that expressed Cre recombinase under the regulation of either a Nestin promoter, namely Nestin-Cre mice (B6.Cg$\mathrm{Tg}[$ Nes-cre $] 1 \mathrm{Kln} / \mathrm{J}$; The Jackson Laboratory), thereby creating glut $3^{\text {flox/+/nestin-Cre+ }}$ mice first, or the $\mathrm{Ca}^{2+} /$ calmodulin-dependent protein kinase $2 \alpha(\mathrm{CaMK} 2 \alpha)$ promoter (B6.Cg-Tg(CaMK2 $\alpha$-cre) T29-1Stl/J; Jackson Laboratory), thereby creating a second line of glut $3^{\text {flox } /+/ \text { CaMK } 2 \alpha-\text { Cre }+}$ mice. Male glut $3^{\text {flox/flox }}$ mice were crossed with female glut $3^{\text {flox } /+/ \text { nestin - Cre }+}$ mice, generating the glut 3 conditional $\mathrm{KO}$ mice designated as glut $3^{\text {flox/flox/nestin - Cre+ }}$ (homozygous KO) and glut $3^{\text {flox/+/nestin-Cre+ }}$ (heterozygous, HT) mice. Because glut $3^{\text {flox/flox }}$ without $\mathrm{Cre}$ in preliminary studies expressed a phenotype no different from the WT $\left(\right.$ glut $3^{+/+}$) despite the introduction of loxP sites in two intronic regions, glut $3^{\text {flox/flox }}$ served as the control (CON) genotype for our subsequent studies. In addition, mating male glut $3^{\text {flox } /+/ \text { CaMK2 } \alpha \text {-Cre }+}$ mice with female glut $3^{\text {flox } /+/ C a M K 2} \alpha$-Cre + mice generated glut $3^{\text {flox/flox/CaMK } 2 \alpha-\mathrm{Cre}+}$ mice. Finally, female glut $3^{\text {flox/flox }}$ mice (which served as $\mathrm{CON}$ ) were crossed with male glut ${ }^{\text {flox/flox/CaMK2 } \alpha \text {-Cre }+}$ mice $(\mathrm{KO})$ to generate glut 3 conditional KO mice designated as glut $3^{\text {flox/flox/CaMK } 2 \alpha-\mathrm{Cre}^{+}}$mice $(\mathrm{KO})$ and glut ${ }^{\text {flox/flox }}$ floxed mice designated as controls $(\mathrm{CON})$ within the same litter.

\section{Genotyping of conditional glut3 deleted mouse lines}

By PCR upon analysis of mouse tail DNA samples, the presence of glut $3^{\text {flox/flox }}$ presented as a 402 bp DNA fragment that served as a control without the presence of Cre, whereas the absence of glut $^{\text {flox/flox }}$, namely WT for glut 3 (glut $3^{+/+}$which is not floxed) produced a 233 bp DNA fragment. Therefore, the heterozygous floxed glut3 gene, namely glut $3^{\text {flox } /+}$, produced two DNA fragments sized 233 bp and 402 bp with the presence of Cre. The presence of Cre was seen as an additional $554 \mathrm{bp}$ DNA fragment, therefore a heterozygous $\left(\right.$ glut $\left.^{\text {flox } /+/ \mathrm{Cre}+}\right)$ deletion (402 bp, $233 \mathrm{bp}$, and $554 \mathrm{bp}$ ) and a homozygous ( glut $^{\text {flox/flox/Cre }+}$ ) deletion (402 bp and $554 \mathrm{bp}$ ) could be detected separately based on the number and size of the DNA fragments generated in both mouse lines (Nestinand $C a M K 2 \alpha-$ ).

Placental studies in glut $^{\text {flox/flox/nestin-Cre+ }}$ and glut $^{\text {flox/flox/CaMK2 } \alpha \text {-Cre+ }}$ mice

Placenta sample preparation

Mice at $18 \mathrm{~d}$ of pregnancy were obtained. Days of pregnancy were designated as described previously; the first day of gestation was considered to
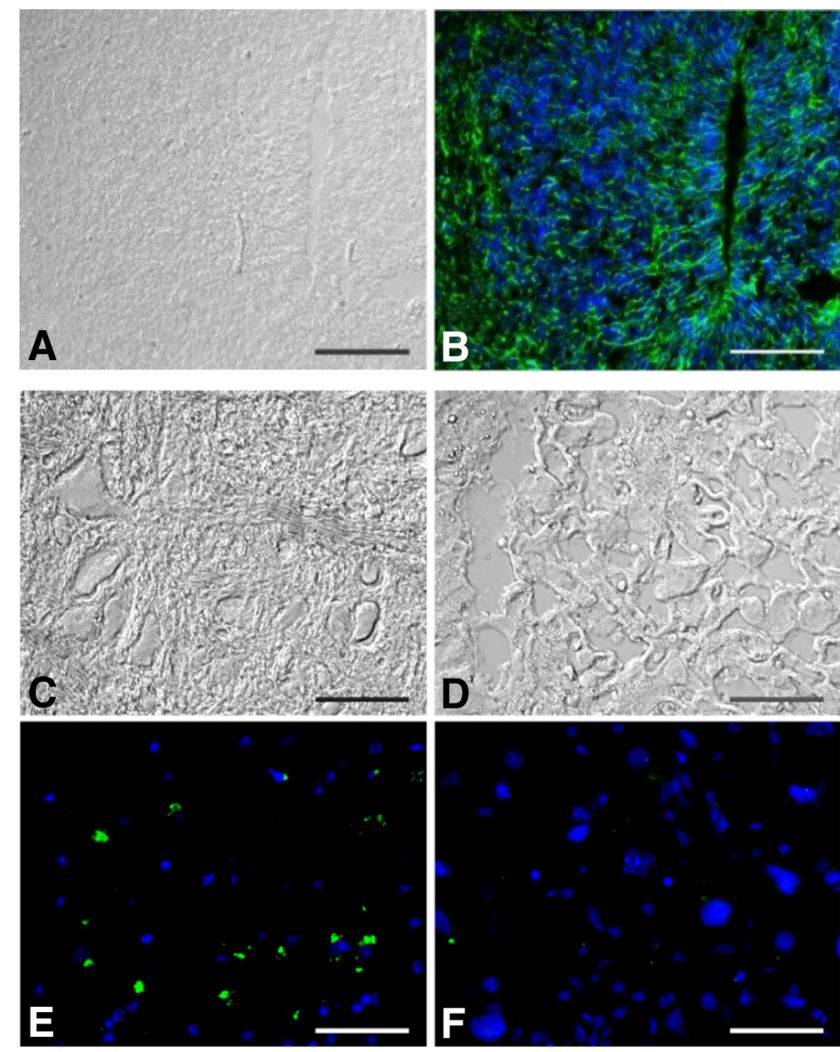

Figure 2. Nestin and CaMK2 $\alpha$ protein in brain $(\boldsymbol{A}-\boldsymbol{C}, \boldsymbol{E})$ and placenta $(\boldsymbol{D}, \boldsymbol{F})$. Nestin expression in CON E13.5 brain $\boldsymbol{A}, \boldsymbol{B}$, Immunofluorescence localization of Nestin $(\boldsymbol{A})$ showing corresponding Nomarski-differential interference contrast (DIC) images. Alexa Fluor 488-conjugated donkey anti-goat lgG (1/500) was applied after the goat anti-Nestin antibody (1/100) in an overnight incubation at $4^{\circ} \mathrm{C}$. DAPI served as the nuclear stain. Nestin protein was expressed in E13.5 brain $(\boldsymbol{B})$. Expression of CaMK2 $\alpha$ in adult brain $(\boldsymbol{C}, \boldsymbol{E})$ and E18 placenta $(\boldsymbol{D}, \boldsymbol{F})$. Immunofluorescence localization of CaMK2 $\alpha(\boldsymbol{E}, \boldsymbol{F})$. Alexa Fluor 488-conjugated donkey anti-goat lgG (1/500 each, Jackson ImmunoResearch Laboratories) was applied after the goat anti-CaMK2 $\alpha$ antibody $(1 / 500)$ during an overnight incubation at $4^{\circ} \mathrm{C}$. DAPI was the nuclear stain. $C, D$, Corresponding Nomarski differential interference contrast (DIC) images. $\boldsymbol{E}, \boldsymbol{F}$, CaMK2 $\alpha$ protein was expressed in brain $(\boldsymbol{E})$, not placenta $(\boldsymbol{F})$

be the day after the vaginal plug was detected (Nagy et al., 2003). The animals were anesthetized with sodium pentobarbital $(50 \mathrm{mg} / \mathrm{kg})$, placenta was removed at laparotomy with hysterectomy, fixed in $4 \%$ paraformaldehyde for immunohistochemistry or frozen in liquid nitrogen for Western blots as described previously (Shin et al., 1998; Ganguly et al., 2007; Zhao et al., 2010).

\section{Localization by immunohistochemical studies}

Placental cryostat sections ( $10 \mu \mathrm{m}$ thickness) were subjected to immunofluorescence staining using Glut1 and Glut3 (1:500 dilution each, RRID:AB_2737340 and RRID:AB_2631293, a gift from Dr. Takata, Gunma University) and Nestin antibodies (1/50 dilution, Neuromics, catalog \#GT15114, RRID:AB_1619688) or CaMK2 $\alpha$ (1/50, Novus Biologicals, catalog \#N BP1-51945, RRID:AB_11037869) and CD34 (endothelial cell marker, 1/100; Abcam, catalog \#ab81289, RRID:AB_1640331) as primary antibodies, followed by corresponding secondary antibodies carrying the fluorescent tags of either Alexa Fluor 488 (Jackson ImmunoResearch Laboratoriess, catalog \#705-545-003, RRID:AB_2340428 for Nestin and CaMK2 $\alpha$; catalog \#711-545-152, RRID:AB_2313584 for Glut3 and CD34) or Alexa Fluor 594 (Jackson ImmunoResearch Laboratories, catalog \#705-585-003, RRID:AB_2340432 for Nestin in double staining with CD34; catalog \#706-585-148, RRID:AB_2340474 for Glut1). 4', 6-diamino-2-phenylindole dihydrochloride (DAPI) was used for DNA staining. Slides with placental sections were examined under a Nikon E-600 fluorescence microscope equipped with a cooled chargedcoupled device camera being controlled by MetaMorph (Molecular De- 


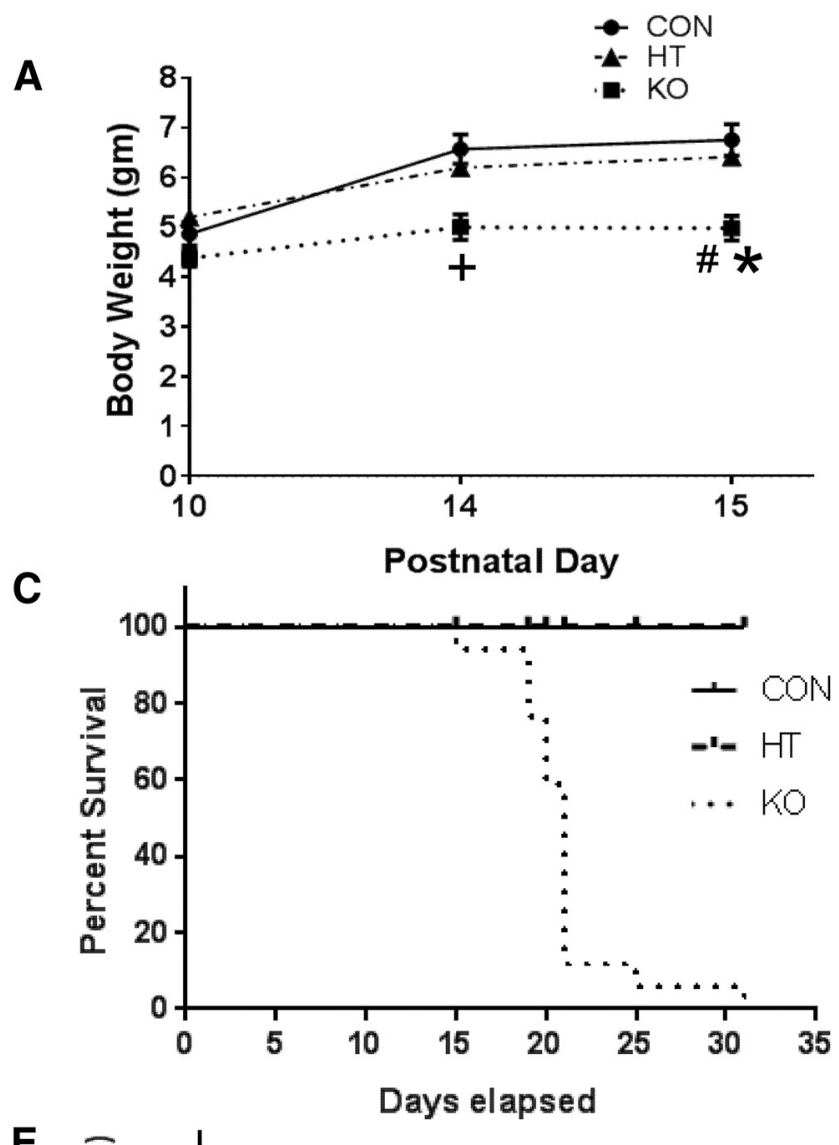

B
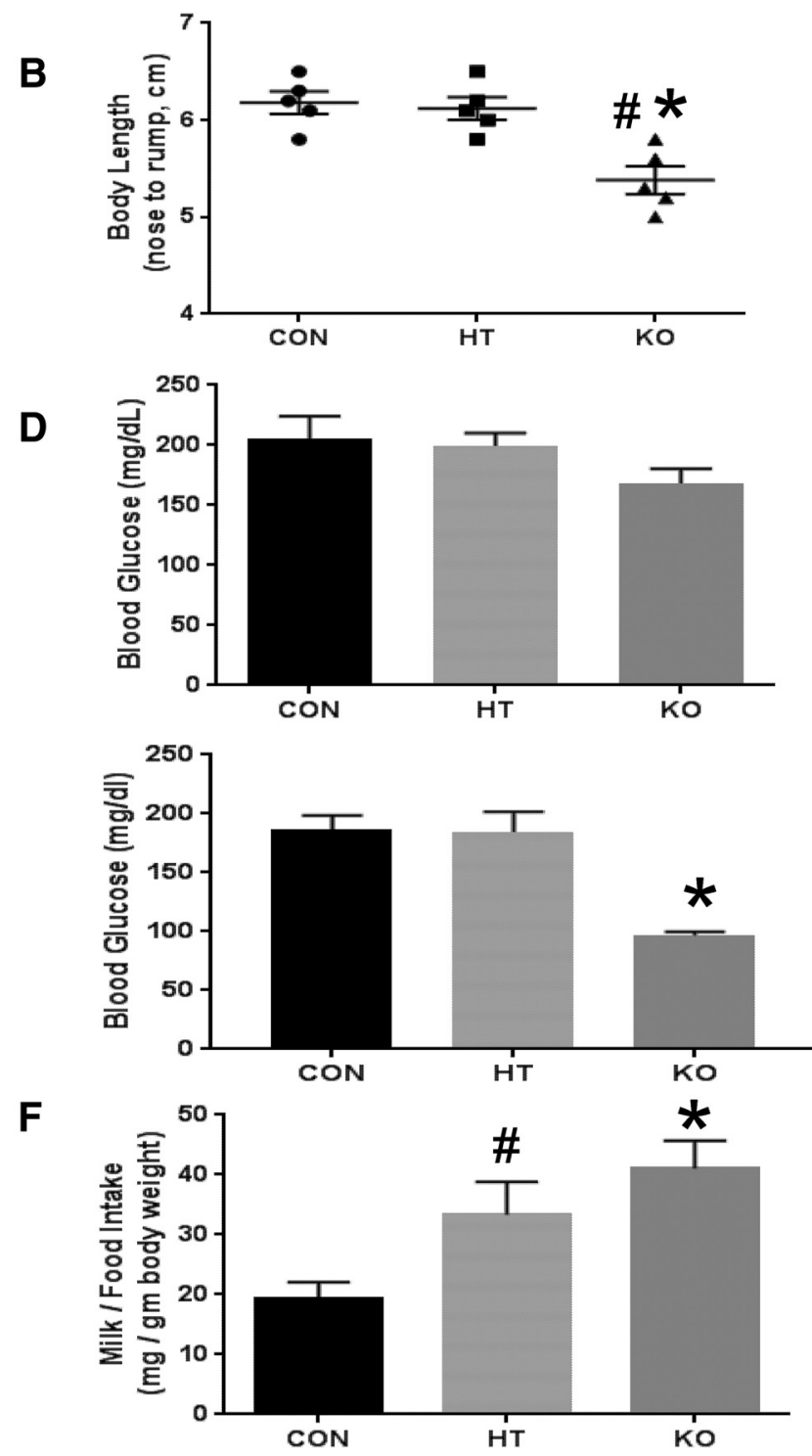

Figure 3. A, Growth curves of pups from three experimental groups. Mouse body weights at PN10, PN14, and PN15 two-way ANOVA followed by Sidak's multiple-comparisons test (genotype, Fstatistic [df: 2, 16] $=6.617, p=0.008 ;$ age, Fstatistic $[$ df; 2,32$]=150.7, p<0.0001$; interaction, Fstatistic [df: 4, 32] $=15.18, p<0.0001)$. In P14, K0 vs CON, $+p=0.0013)$ and in P15, K0 vs $\mathrm{CON},{ }^{*} p=0.0002$ and KO vs $\mathrm{HT}$, \#p $=0.0149 . B$, Nose-rump length: Glut3 $\mathrm{KO}$ mice demonstrate reduced length compared with CON and HT (one-way ANOVA, F statistic (df: 2, 12) $=12.62$, $p$-value $=0.001$; and Fisher's PLSD test, ${ }^{*} p=0.007 \mathrm{vs} \mathrm{CON}, \# p=0.0013$ vs HT, $n=5$ in each group). C, Survival curves for the CON, HT, and K0 groups. Comparison of survival curves by log-rank (Mantel-Cox, $\chi^{2}=16.67$ [df: 2]) test shows a significant difference in KO compared with CON and HT, $p=0.0002$. D, Blood glucose in the basal state at PN15 (top, $n=5$, in each group) and PN21 (bottom, $n=22$ in CON, $n=11$ in HT and $n=4$ in KO). There is no difference among groups at PN15, but significant difference at PN21 in KO compared with CON and HT (one-way ANOVA, Fstatistic [df: 2,34] $=4.849, p$-value $=0.014$; and Fisher's PLSD test, ${ }^{*} p<0.02$ vs CON and HT). E, Brain weight at PN15. Brains of glut 3 KO mice are smaller than CON or HT mice (one-way ANOVA, Fstatistic [df: 2,25$]=16.17, p$-value $<0.0001$; and Fisher's PLSD test, ${ }^{*} p<0.0007$ vs CON and HT, 10 in K0, $n=13$ in CON, 5 in HT). $F$, Milk intake in milligrams per gram body weight at PN15. (0ne-way ANOVA, F statistic $[\mathrm{df}: 2,19]=7.607, p$-value $=0.0037$; and Fisher's PLSD test, ${ }^{*} p=0.0023$ vs CON, \#p $=0.017$ vs CON; $n=4$ in KO, $n=12$ in CON, $n=6$ in HT).

vices, RRID:SCR_002368) imaging software as described previously (Shin et al., 2004).

Placental protein concentrations by Western blot

At embryonic day 18 (E18), placentas were homogenized in cell lysis buffer (Cell Signaling Technology). Homogenates (30 $\mu \mathrm{g}$ of protein) were subjected to gel electrophoresis and transferred to nitrocellulose membrane filters (Bio-Rad) as described previously (Shin et al., 1997, 2004). The blotted membranes were incubated in the primary antibodies consisting of the rabbit anti-Glut1 and anti-Glut3 (for Glut1, 1/1000, Abcam, catalog \#ab652, RRID:AB_305540; Glut3 at 1/1000, Takata, RRID:AB_2631293) with mouse anti-vinculin antibody as an internal loading control (1/5000; Sigma-Aldrich, catalog \#V9131, RRID:AB_477629) on the same membrane. The proteins were visualized using a Typhoon 9410 molecular imager (GE Healthcare
Biosciences), quantified by using ImageQuant 5.2 software (GE Healthcare Biosciences) and normalized to vinculin.

Functional glucose transport studies

Mice received $12 \mu \mathrm{Ci}$ of 2-deoxy-D- $\left[1-{ }^{14} \mathrm{C}\right]$ glucose (PerkinElmer). Glucose concentration and radioactivity were assessed and transplacental and intraplacental glucose transport and phosphorylation were calculated as described previously (Ganguly et al., 2012).

Postnatal phenotypic studies in glut $3^{\text {flox/flox/nestin-Cre+ }}$ mice Milk intake measurement

Glut $3^{\text {flox/flox }}$ is referred to as glut $3^{+/+}(\mathrm{CON})$, glut $3^{\text {flox } /+/ \text { Cre }+}$ as glut $3^{+1-}$ (HT), and glut $3^{\text {flox/flox/Cre }+}$ as glut $3^{-1-}$ (homozygous KO) conditional genotypes. Milk intake by pups reared by mothers on regular 

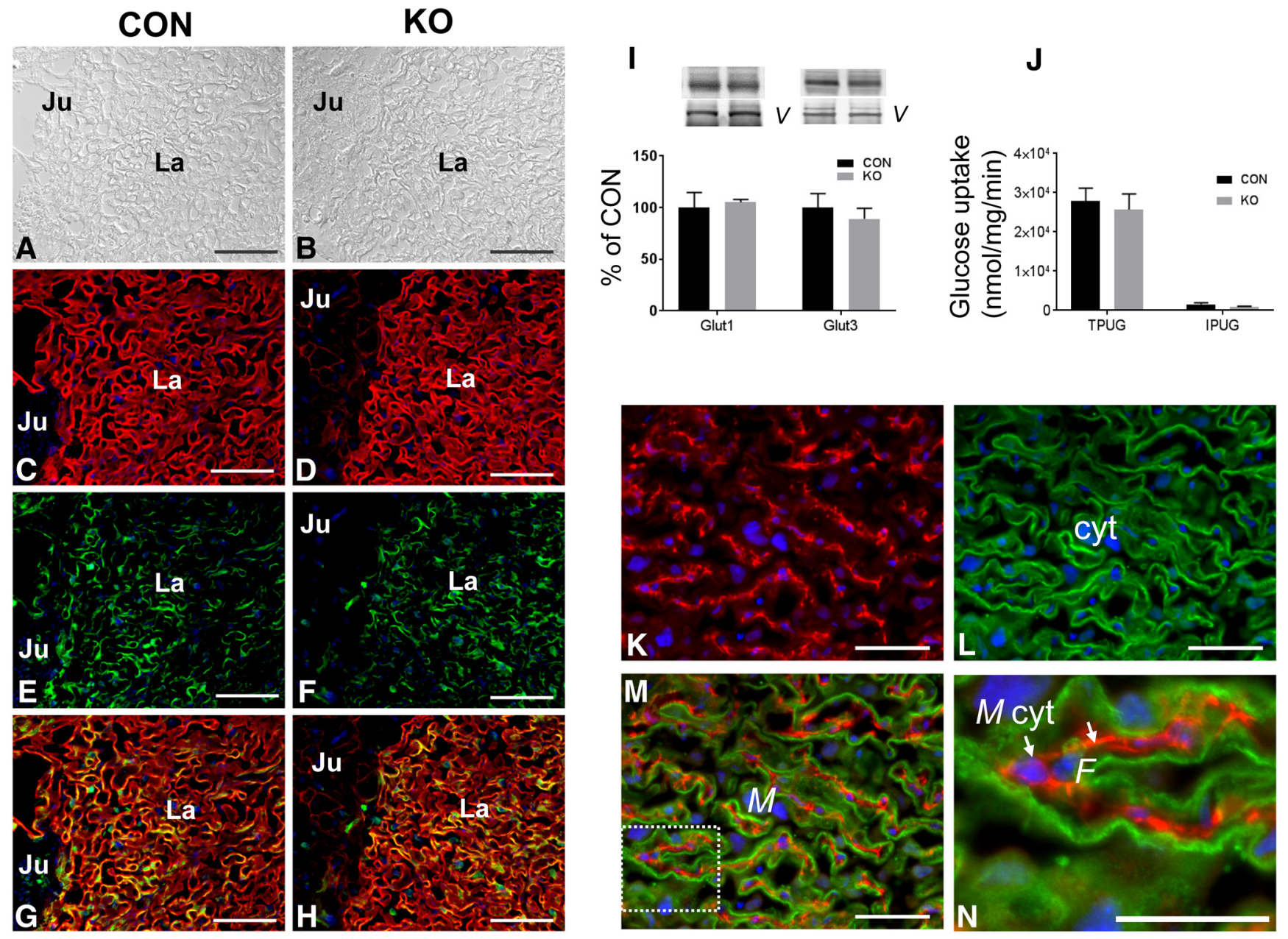

Figure 4. Glut1, Glut3, and Nestin in E18 placenta. Immunofluorescence localization of Glut1 and Glut3 proteins $(\boldsymbol{A}-\boldsymbol{H})$ and $G$ lut 3 and $\operatorname{Nestin}(\boldsymbol{K}-\boldsymbol{N}),(\mathrm{CON}: \boldsymbol{A}, \boldsymbol{C}, \boldsymbol{E}, \boldsymbol{G} ; \mathrm{KO}: \boldsymbol{B}, \boldsymbol{D}, \boldsymbol{F}, \boldsymbol{H}) . \boldsymbol{A}$ and $\boldsymbol{B}$ show corresponding differential interference contrast (DIC) images. Glut1 protein $(\boldsymbol{C}, \boldsymbol{D})$ was expressed in junctional (Ju) and labyrinthine regions (La), whereas $G$ lut3 protein $(\boldsymbol{E}, \boldsymbol{F})$ was expressed in the labyrinthine region alone. There was no difference in the expression pattern of Glut 1 and Glut 3 in the labyrinthine region between $\mathrm{CON}$ and K0. $K$ shows Nestin expression. $\boldsymbol{L}$ shows Glut 3 expression. $M$ shows double exposed-images for both Nestin and Glut3. Nestin (red) and Glut3 ( green) are shown separately as well. $N$, Magnified view from the rectangle in $M$. Glut 3 is expressed in the maternal blood space within syncytiotrophoblasts, whereas Nestin is expressed in the fetal capillary space. Positive staining of Nestin is seen in the endothelial cells lining the fetal capillary (arrows). $M$, Maternal blood space; F, fetal capillary; Cyt, cytotrophoblast. Scale bars, $\boldsymbol{A}-\boldsymbol{H}, 100 \mu \mathrm{m} ; \boldsymbol{K}-\boldsymbol{N}, 50 \mu \mathrm{m}$. I, Western blot analysis of Glut1 and Glut3 proteins in placenta (E18). Top, Representative Western blots. Bottom, Densitometric quantification of corresponding proteins shown as percent of $\mathrm{CON}$. There was no difference between $\mathrm{CON}$ and K0 mice in Glut 1 ( $t$ test, $t$ statistic [df: 4 ] $=0.38$, $p$-value $=0.72$ ) and Glut3 (t statistic [df: 4$]=0.645, p$-value $=0.554, n=3$ each for CON or K0, vinculin (v) is an endogenous protein as an internal CON.J, Trans-placental uptake of glucose (TPUG; t statistic [df: 17] $=0.43, p$-value $=0.67$ ) and intraplacental uptake of glucose (IPUG; $t$ statistic [df: 18] $=0.71, p$-value $=0.13$ ) shown as glucose uptake in $\mathrm{nmol} / \mathrm{mg} / \mathrm{min}$. There is no difference between CON and KO groups by unpaired $t$ test. $n=9$ for $\mathrm{KO}, n=10$ for $\mathrm{CON}$.

chow diet from the CON $\left(\right.$ glut $\left.^{+/+}\right)$, $\mathrm{HT}\left(\right.$ glut $\left.^{+/-}\right)$, and $\mathrm{KO}\left(\right.$ glut $\left.^{-l^{-}}\right)$ groups was assessed as described previously (Fukushima et al., 2006; Shin et al., 2012; Gibson et al., 2015).

\section{Blood glucose measurement}

Following inhalational anesthesia with isoflurane, whole blood from PN15 and PN21 pups was collected from the jugular vein and glucose measured with Hemo Cue Glucose 201 glucometers.

\section{Anthropometric and lifespan measurements}

Body weights were determined at PN7, PN10, PN14, PN15, and PN21. Further, at PN15, pups were deeply anesthetized under isoflurane, and, after collection of blood for plasma glucose, body length was measured and brains were harvested. Various other tissues were also collected. The lifespan of mice was monitored and survival curves derived by GraphPad Prism 7 (RRID:SCR_002798).

\section{Dietary intervention}

Glut3 KO (Nestin) and CON mice were given either a ketogenic (test) diet ( protein $24.8 \%$, fat $57.3 \%$, fiber $9.6 \%$, carbohydrate $0 \%$; 5 TJQ, test diet) or a regular chow (lab) diet (protein $21 \%$, fat $6.3 \%$, fiber $4.5 \%$, nitrogen free extract $53.5 \%$; 5053) during $15 \mathrm{~d}$ to $21 \mathrm{~d}$ of gestation (embryonic/fetal exposure) and lactation (exposure in suckling phase, PN1 to until alive; KO pups were at times either dead or cannibalized).

Glut3 expression in various tissues

To assess the degree of Glut3 expression in different tissues, various organs were collected at PN15. Thirty micrograms of tissue homogenates was subjected to Western blot analysis using the anti-Glut3 antibody as described previously (Dai et al., 2017).

Retinal and testicular studies

Mouse eyes and testicles at PN15 were subjected to immunofluorescence staining using Glut1 and/or Glut3 antibodies with DAPI for nuclear staining.

Prenatal and postnatal brain studies in glut $^{\text {flox/flox/nestin-Cre+ }}$ mice

Brain sample preparations

Mice were anesthetized with sodium pentobarbital administered intraperitoneally, following which fetal (E18) or postnatal (PN1, PN15) 

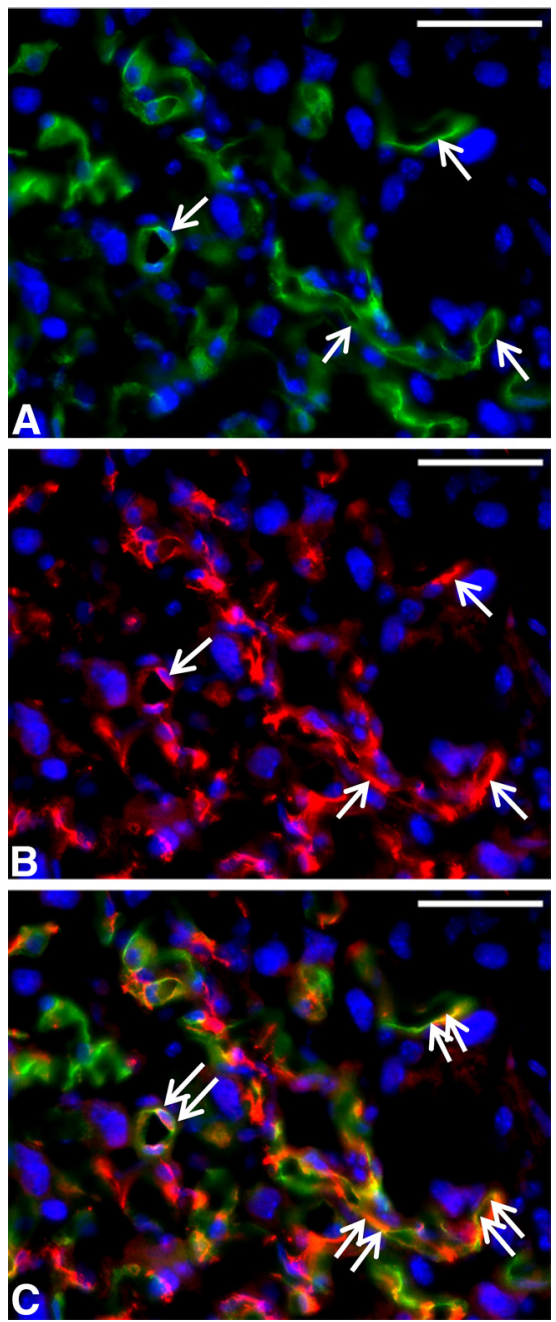

Figure 5. Immunofluorescence localization of CD34 and Nestin proteins in E18 placenta. Alexa Fluor 488-conjugated donkey anti-rabbit lgG (1/250) and Alexa Fluor 594-conjugated donkey anti-goat lgG (1/250) were applied after the rabbit anti-CD34 (1/50) and goat antiNestin antibodies (1/50, each) over a $3 \mathrm{~h}$ incubation at room temperature. DAPI served as the nuclear stain. CD34 ( $\boldsymbol{A})$ and Nestin $(\boldsymbol{B})$ proteins were expressed in the membrane of endothelial cells (arrows). A double-exposure image shows colocalization of CD34 (green) and Nestin (red) in endothelial cells of fetal capillaries (double arrows in C). Scale bars, $50 \mu \mathrm{m}$.

brains were procured, fixed with $4 \%$ paraformaldehyde for immunohistochemistry or frozen in liquid nitrogen for Western blots as described previously (Shin et al., 1998; Ganguly et al., 2007; Zhao et al., 2010). Whole brains were embedded in $2 \%$ agar or in optimal cutting temperature compound for immunohistochemical analysis (Fung et al., 2010; Zhao et al., 2010). Some brains were embedded in paraplast wax for in situ hybridization histochemistry (Shin et al., 2012).

\section{Brain protein concentrations by Western blot analysis}

At E18 or PN15, brain homogenates were subjected to Western blots as described previously (Shin et al., 2004). The blotted membranes were sequentially incubated in primary antibodies consisting of the rabbit antiGlut1, Glut4 and Glut8 (1/1000, each, Abcam, catalog \#ab652, RRID: AB_305540; catalog \#ab654, RRID:AB_305554; catalog \#ab169779, RRID: AB_2737342), Glut3 (1/500, Takata, RRID:AB_2631293), synaptophysin (1/1000, Millipore, catalog \#04-1019, RRID:AB_1977519), $\beta$-tubulin (1/ 1000, Covance, catalog \#MMS-435P, RRID:AB_2313773), Map2 (1/1000, Neuromics, catalog \#MO22116, RRID:AB_2737343), MCT2 (1/100, Santa Cruz Biotechnology, catalog \#sc-271093, RRID:AB_10609511) antibodies with mouse anti-vinculin (Sigma-Aldrich, catalog \#V9131, RRID: AB_477629), or anti-actin (Abcam, catalog \#ab179467, RRID:AB_2737344) antibodies serving as internal loading controls on the same membranes, allowing normalization of signals to vinculin or actin using ImageQuant version 5.2 software.

\section{Localization by immunohistochemical studies}

Sagittal brain sections $(10 \mu \mathrm{m})$ by a cryostat (RM2235, Leica Microsystems) or coronal brain sections ( $30 \mu \mathrm{m}$ thickness) by a vibratome (VT 1000S, Leica Microsystems) were subjected to microscopy as described previously (Shin et al., 2004; Zhao et al., 2010). To visualize immunofluorescence staining, rabbit anti-Glut3 (RRID:AB_2631293) and guinea pig anti-Glut1 (1:500, Dr. Takata, RRID:AB_2737340), goat anti-Nestin (1/100, Neuromics, catalog \#GT15114, RRID:AB_1619688), rabbit antisynaptophysin (1/1000, Millipore, catalog \#04-1019, RRID:AB_1977519) and mouse anti-Map2 (1/1000, Neuromics, catalog \#MO22116, RRID: AB_2737343) were used as primary antibodies, followed by corresponding secondary antibodies carrying the fluorescence tags of either Alexa Fluor 488 (Jackson ImmunoResearch Laboratories, catalog \#711545-152, RRID:AB_2313584 for Glut3; catalog \#715-545-150, RRID: AB_2340846 for MAP2) or Alexa Fluor 594 (Jackson ImmunoResearch Laboratories, catalog \#706-585-148, RRID:AB_2340474 for Glut1; catalog \#711-585-152, RRID:AB_2340621 for synaptophysin).

\section{Dendritic and axonal integrity analysis: Golgi staining of} brain sections

Golgi staining was performed according to the manufacturer's instructions (FD Neuro Technologies) with slight modifications to improve impregnation. Briefly, after anesthetizing mice with intraperitoneal sodium pentobarbital $(50 \mathrm{mg} / \mathrm{kg}$ ), whole brains of mice were removed and immersed in the impregnation solution. To capture a high density of dendritic spines, the tissue container was gently rotated 3-4 times every day during the 3 week period of impregnation. To ensure uniformity of staining of neurons in all sections, $100 \mu \mathrm{m}$ sections using a cryostat (Reica CM1850, Leica Microsystems) were chosen and treated alike at the same time using the Rapid Golgi Stain Kit (FD Neuro Technologies) before initial visualization under low magnification to confirm complete staining of the dendritic networks. The pyramidal neurons that appeared complete, demonstrating a robust cross-section were selected for spine counting by blinding the investigators to the genotype of the brain section. Using Nikon E-600 microscope, $Z$-stacks of apical dendrites (optical section thickness $=0.125 \mu \mathrm{m}$ ) were focused at $50 \mu \mathrm{m}$ distance from the soma-dendritic boundary of cortical pyramidal neurons. The number of primary dendritic spines was counted on five continuous segments, each segment measuring $10 \mu \mathrm{m}$ in length of dendrites (Poeggel et al., 2003; Mitra et al., 2005). The number and total length of secondary dendritic branches that emerged from primary dendrites within $100 \mu \mathrm{m}$ distance from the soma were also evaluated (Ogino et al., 2017). The MetaMorph image analysis system was used for these assessments (Molecular Devices, RRID:SCR_002368).

\section{Functional glucose transport by PET scanning}

Pups (PN15) were injected intraperitoneally with $\sim 25 \mu \mathrm{Ci}$ of ${ }^{18} \mathrm{~F}$ labeled 2-fluoro-2-deoxyglucose $\left({ }^{18} \mathrm{~F}-\mathrm{FDG}\right.$; obtained from the UCLA Department of Nuclear Medicine) while conscious, PET imaged, and the images were analyzed and validated as described previously (Loening and Gambhir, 2003; Taschereau et al., 2014; Dai et al., 2017).

\section{Quantification of GABA, glutamine, and glutamic acid by} combined liquid chromatography/tandem mass spectrometry

Brain tissue homogenates were aliquoted $(50 \mu \mathrm{l})$ into microcentrifuge tubes to which was added a solution of internal standards: 400 pmol of both 6-aminohexanoic acid (6AHA) and hexadeuterated GABA (2H6-GABA) in $10 \mu \mathrm{l}$ of aqueous $0.1 \%$ formic acid, followed by methanol $(700 \mu \mathrm{l})$. After vortexing and incubation on ice (30 min) the samples were centrifuged $(16,000 \times g, 5 \mathrm{~min})$ and the supernatants transferred to clean tubes and dried in a vacuum concentrator (tube set 1, TS1). Water $(100 \mu \mathrm{l})$ was added to the dried residues, the samples were vigorously mixed and $50 \mu \mathrm{l}$ of each was transferred to another microcentrifuge tube (tube set 2, TS2). Acetic anhydride (50 $\mu \mathrm{l})$ was added to each TS1 tube, samples were mixed, heated at $60^{\circ} \mathrm{C}$ for $60 \mathrm{~min}$, dried in a vacuum concentrator, and then water $(150 \mu \mathrm{l})$ was added. The TS2 tubes were also dried in a vacuum concentrator 


\section{Brain (E18D)}

\section{A}
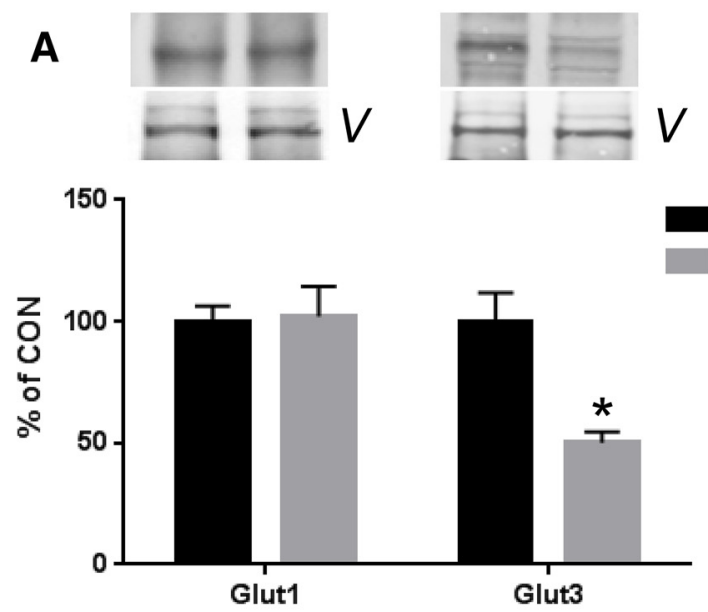

\section{Brain (PN1D) CON}
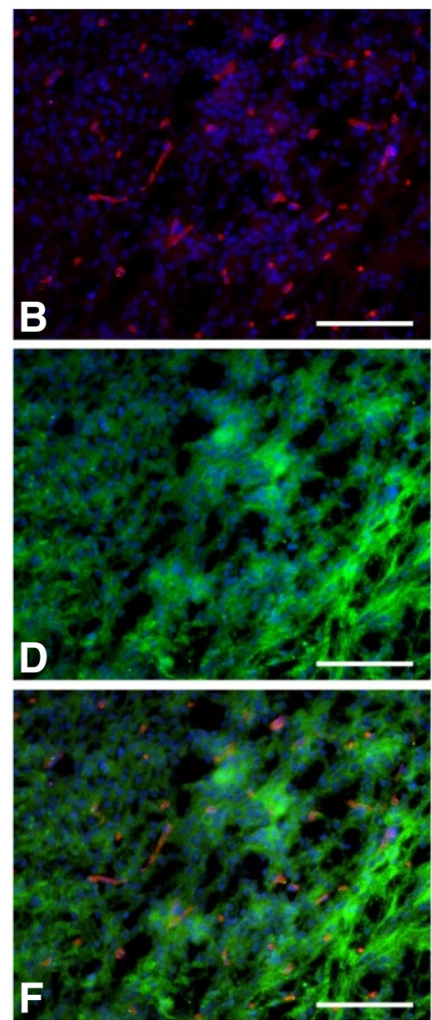

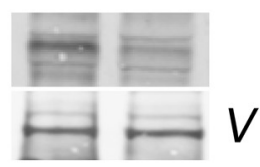

V

CON

$\mathrm{KO}$
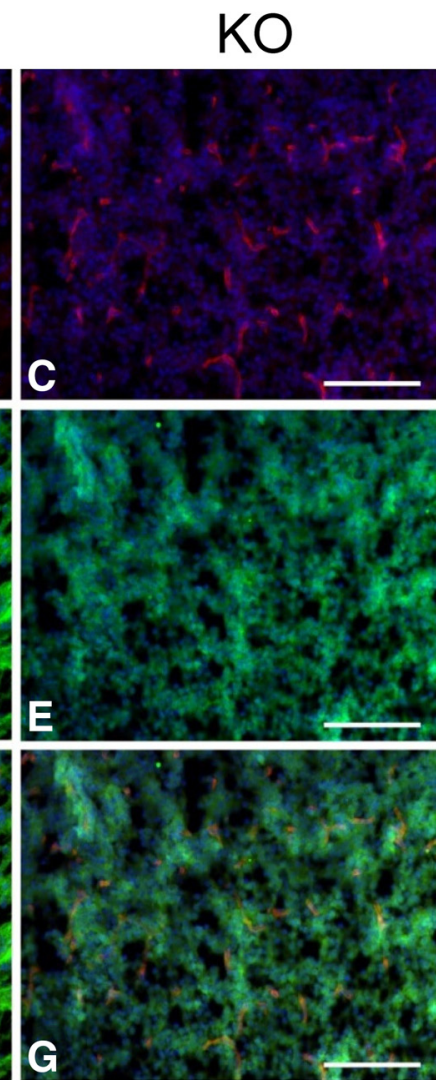

Brain (PN15D)

H
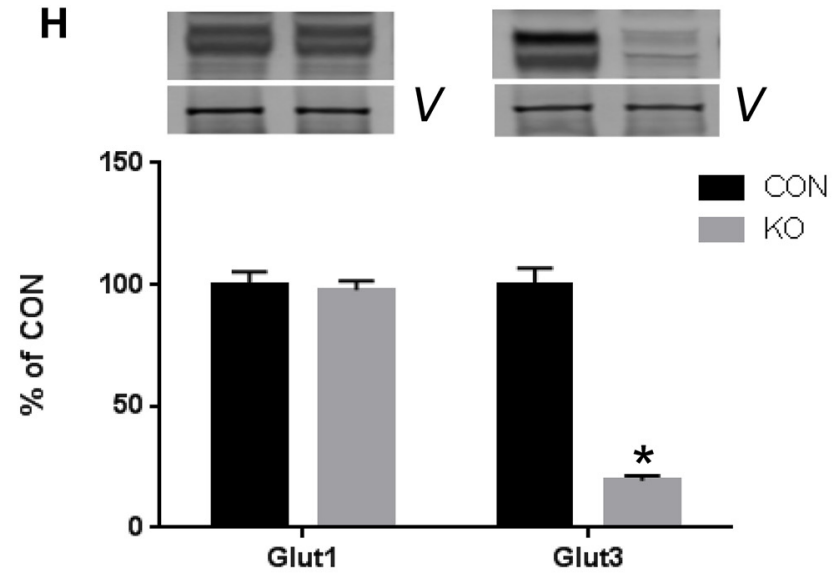

Brain (PN15D)CON
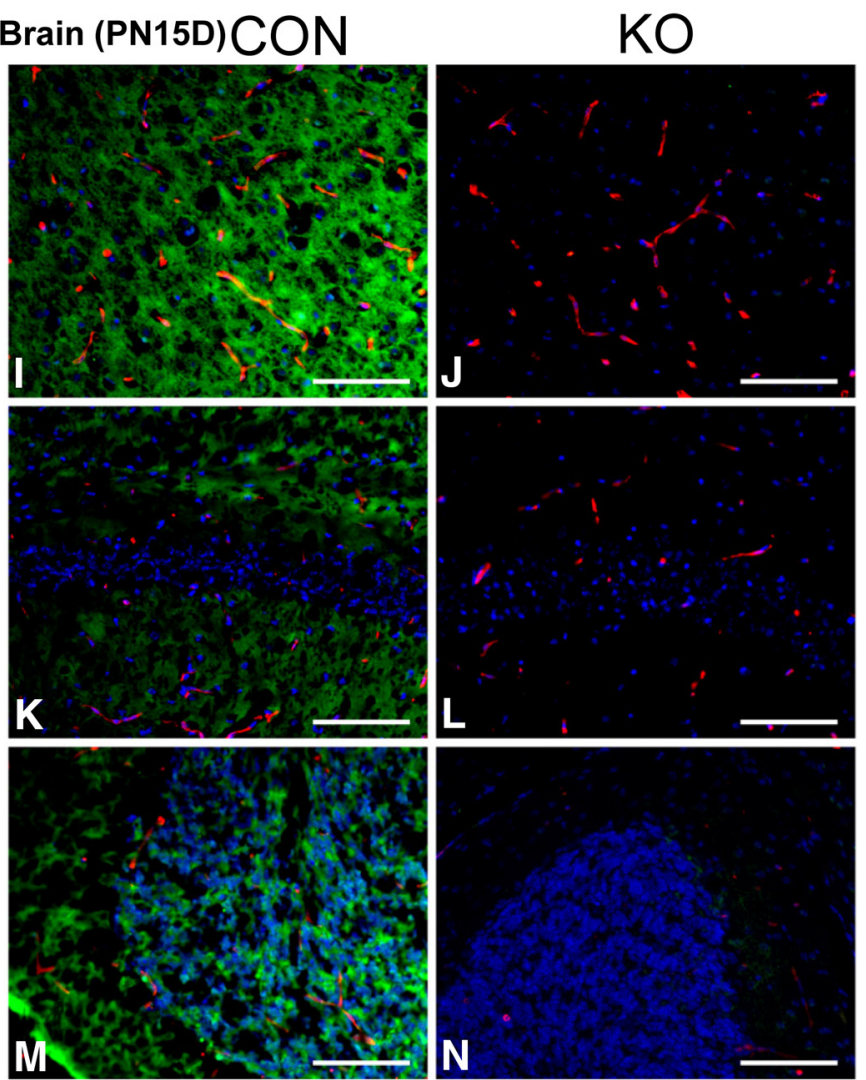

Figure 6. Expression of Glut1 and Glut3 in the brain at E18 $(\boldsymbol{A}), \mathrm{P1}(\boldsymbol{B}-\boldsymbol{G})$, and PN15 $(\boldsymbol{H}-\boldsymbol{N})$. Western blot analysis of Glut1 and Glut3 proteins in E18 $(\boldsymbol{A})$ and PN15 $(\boldsymbol{H})$ brains is shown. Top, Representative Western blots. Bottom, Densitometric quantification of corresponding proteins. $A$, Expression of the glut 3 gene is significantly decreased in the brains of $E 18 \mathrm{~K} 0$ mice $(t$ test, $t$ statistic [df: 4 ] $=3.95,{ }^{*} p$-value $=0.017$ ), whereas there was no difference between CON and K0 mice with Glut1 ( $t$ statistic [df: 4$]=0.1625, p$-value $=0.88$ ), $n=3$ for each group. $\boldsymbol{H}$, Expression of the glut3 gene is significantly decreased in PN15 as well ( $t$ statistic [df: 16$]=13.92,{ }^{*} p$-value $<0.0001$ ), whereas there was no difference between CON and K0 mice with Glut1 ( $t$ statistic [df: 15] $=$ $0.3644, p$-value $=0.72$ ). Vinculin (v) served as an internal CON, $n=11$ for KO, $n=7$ for CON. Immunofluorescence localization of Glut1 and Glut3 proteins in PN1 brain (CON: $\boldsymbol{B}, \boldsymbol{D}, \boldsymbol{F} ; \mathrm{KO}: \boldsymbol{C}, \boldsymbol{E}, \boldsymbol{G}$ ) and PN15 brain (CON: $I, K, M ; K 0: J, L, N)$. Glut1 protein was expressed in capillaries (both CON and KO). There are no differences in the expression of Glut1 ( $B, C$, whereas Glut3 protein was reduced in $K 0(\boldsymbol{E})$ versus $\mathrm{CON}(\boldsymbol{D})$. At PN15, Glut1 protein (red) was expressed in capillaries of the cortex $(\boldsymbol{I}, \boldsymbol{J})$, hippocampus $(\boldsymbol{K}, \boldsymbol{L})$, and cerebellum $(\boldsymbol{M}, \boldsymbol{N})$ (both CON and KO). Glut3 protein (Alexa Fluor 488$)$ was dramatically decreased in the cortex, hippocampus, and cerebellum of K0 mice. Scale bars, $100 \mu \mathrm{m}$.

and then treated with butanolic $\mathrm{HCl}\left(3 \mathrm{~N}, 100 \mu \mathrm{l}, 60^{\circ} \mathrm{C}, 60 \mathrm{~min}\right)$, following which the contents were dried again in a vacuum concentrator. After vigorous mixing, the contents of each TS1 tube were transferred to the corresponding TS2 tube. The contents of the TS2 tubes were thoroughly mixed, centrifuged $(16,000 \times g, 5 \mathrm{~min})$, and the supernatants transferred to HPLC injector vials. Included in the batch of samples was a series of standards prepared in water $(50 \mu \mathrm{l})$ containing the same amounts of internal standards but varying quan- tities of GABA, E, and Q $(0,0.1,0.25,0.5$, and $1.0 \mathrm{nmol}$ each $)$ in duplicate. These 10 standards were processed in an identical fashion as described above for the brain samples.

Aliquots of the samples $(5 \mu \mathrm{l})$ were injected onto a reverse-phase HPLC column (Phenomenex Kinetex XB-C18, $2.1 \times 100 \mathrm{~mm}, 1.7 \mu \mathrm{m}$ particle size, $100 \AA$ pore size) equilibrated in solvent A (water/formic acid, 100/0.1, v/v) and eluted with an increasing concentration of solvent B (acetonitrile/formic acid, 100/0.1, v/v; min/\%B, 0/0, 5/0, 30/30, 31/100, 


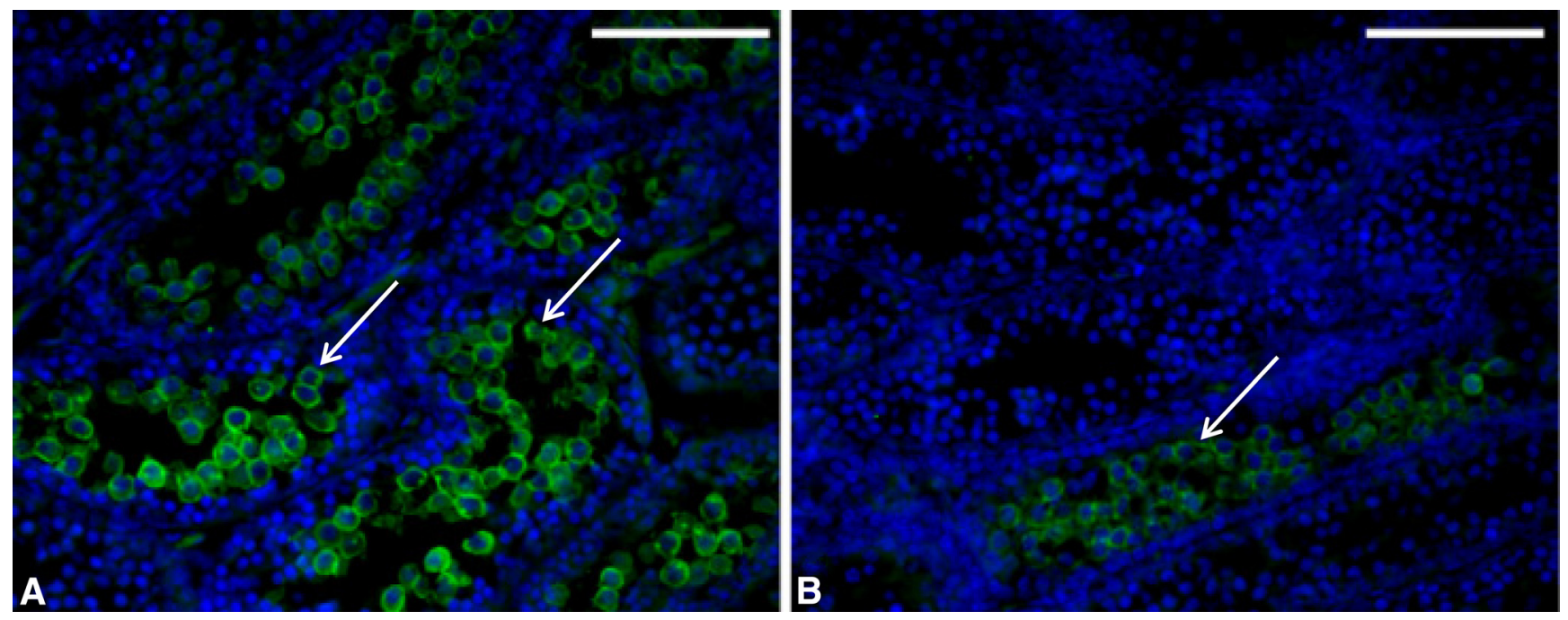

Figure 7. Immunofluorescence localization of Glut3 protein in testis of PN15 mice $(\boldsymbol{A}, \boldsymbol{B})$. Alexa Fluor 488-conjugated donkey anti-rabbit lgG (1/500) was applied after the rabbit anti-Glut3 antibody $\left(1 / 500\right.$, each) during overnight incubation at $4^{\circ} \mathrm{C}$. DAPI was added for staining the nucleus. The expression of Glut 3 is dramatically decreased in spermatids of K0 mice $(\boldsymbol{B})$, whereas $\mathrm{CON}$ mice expressed Glut3 protein in spermatids $(A)$. Arrows indicate Glut3-positive spermatids. Scale bars, $100 \mu \mathrm{m}$.
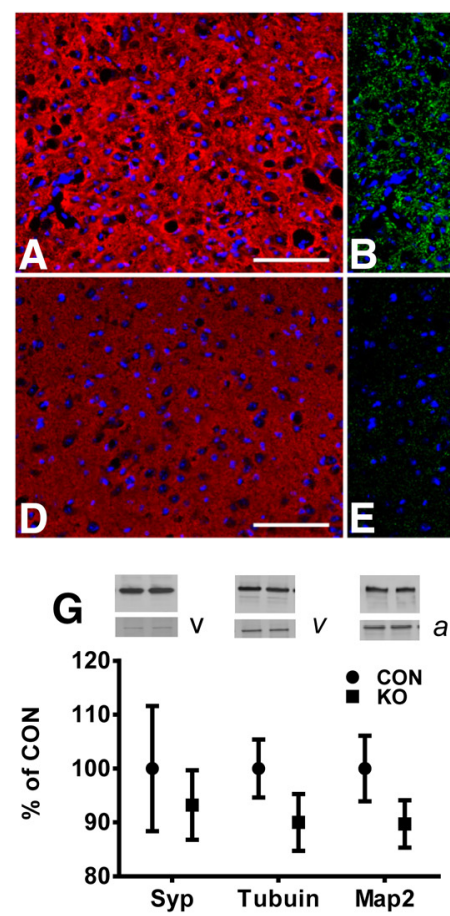
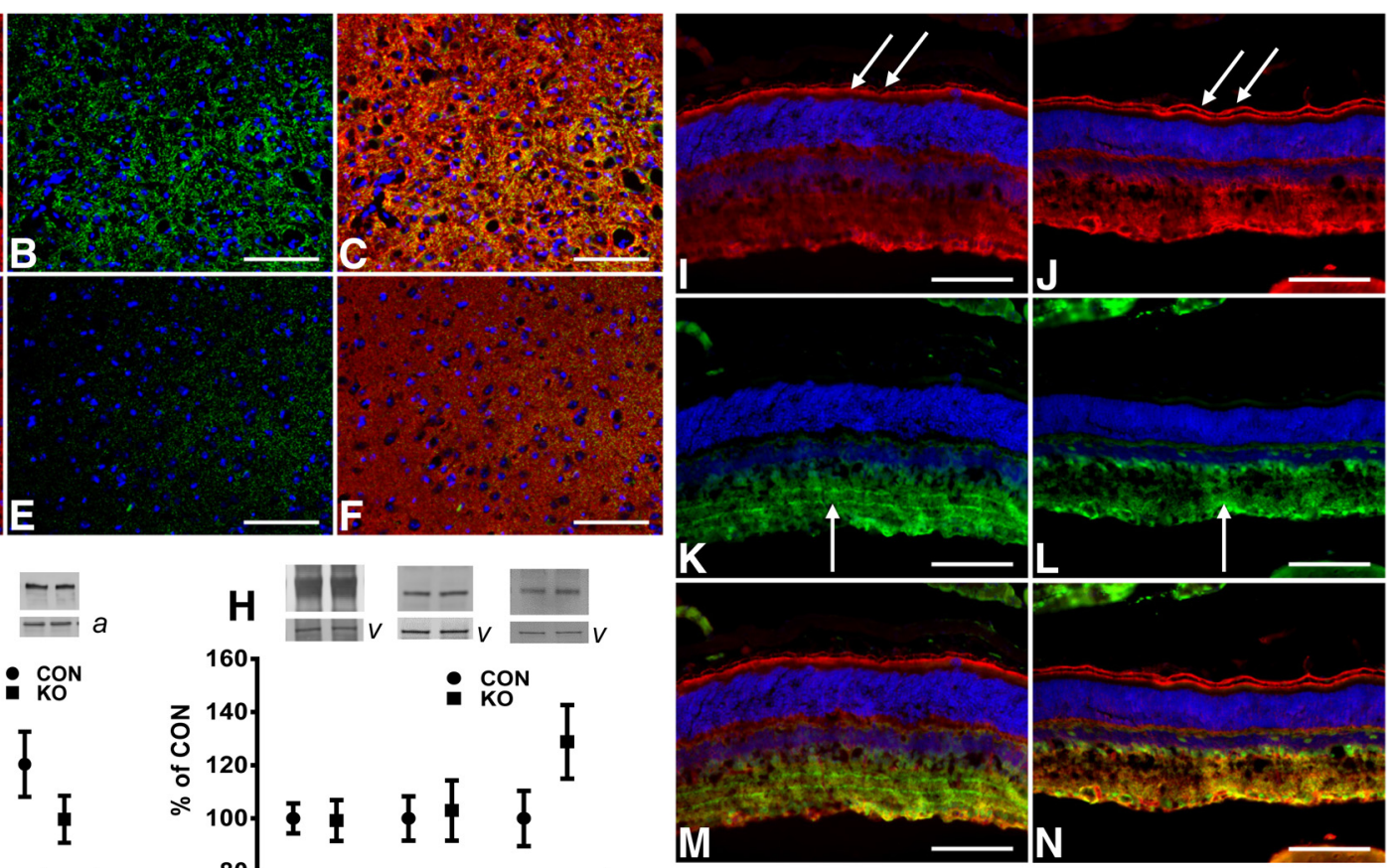

Figure 8. Synaptophysin (Syp), Map2, Tubulin, Glut4, Glut8, and MCT2 genes in brain at PN15. Immunofluorescence localization of synaptophysin ( $\boldsymbol{A}, \boldsymbol{D})$ and Map2 (B, $\boldsymbol{E})$ proteins (CON: $\boldsymbol{A}-\boldsymbol{C}$; KO: $\boldsymbol{D}-\boldsymbol{F}$ ). Synaptophysin and Map2 were reduced in the brainstem of $\mathrm{KO}$ mice $(\boldsymbol{D}, \boldsymbol{E})$ compared with CON. $\boldsymbol{A}, \boldsymbol{B}, \boldsymbol{C}$, and $\boldsymbol{F}$ show yellow fluorescence from double exposures of synaptophysin (red) and Map2 (green). $\mathbf{G}, \boldsymbol{H}$, Western blot analysis of synaptophysin, tubulin, and Map2 proteins $(\boldsymbol{G})$ and Glut4, Glut8, and MCT2 proteins $(\boldsymbol{H})$. Top, Representative Western blots. Bottom, Densitometric quantification of corresponding proteins. There was no significant difference between $C O N$ and KO mice in the expression of synaptophysin ( $t$ statistic [df: 16] $=0.54, p$-value $=0.60)$, tubulin $(t$ statistic [df: 16] $=1.313, p$-value $=0.21$ ) and Map2 ( $t$ statistic [df: 16] $=1.41$, $p$-value $=0.18$ ) by unpaired $t$ test, $n=10$ in K0, $n=8$ in CON. In addition, the expression of MCT2 ( $t$ statistic [df: $16]=1.6, p$-value $=0.13$ ) was not different in K0 compared with CON. $n=9$ in K0, $n=7$ in CON. Vinculin (v) and actin (a) were used as internal CONs. Immunofluorescence localization of Glut1 and Glut3 proteins in retina at PN15 is shown. Glut1 protein is mainly expressed in the retinal pigment epithelium ( $I, J$, arrows) in both CON $(I)$ and KO $(J)$. However, Glut3 was dramatically decreased in the inner plexiform layer of K0 mice. Arrows in $K$ and $\boldsymbol{L}$ indicate Glut3 immunoreactivity. $\boldsymbol{M}$ and $\boldsymbol{N}$ show double exposure of Glut1 and Glut3 proteins in retina. CON: $\boldsymbol{I}, \boldsymbol{K}, \boldsymbol{M} ; \mathrm{KO}: \boldsymbol{J}, \boldsymbol{L}, \boldsymbol{N}$. Scale bars, $100 \mu \mathrm{m}$.

$32 / 0$, and $40 / 0$ ). The effluent from the column was directly connected to an electrospray ion source attached to a triple quadruple mass spectrometer (Agilent Technologies, 6460) scanning in the positive ion multiple reaction monitoring mode with standard resolution settings (FWHM 0.7 ) using previously optimized conditions for the following transitions: acetyl (a)-Q, 189 $\rightarrow 130,84$ (retention time (Rt) $4.5 \mathrm{~min}$ ); a-E, 190 $\rightarrow 130$,
84 (Rt $5.2 \mathrm{~min}$ ); a-6AHA, $174 \rightarrow \mathbf{1 1 4}$ (Rt $16.7 \mathrm{~min}$ ); GABA-butyl ester (be), $160 \rightarrow 143,87$ (Rt $18.7 \mathrm{~min}$ ); and ${ }^{2} \mathrm{H}_{6}$-GABA-be, $166 \rightarrow \mathbf{9 3}$ (Rt 18.7 min). Peak areas were measured using instrument manufacturer supplied software (Agilent Technologies MassHunter: quantitative analysis subroutine), and were manually checked and adjusted when necessary. The amount of each analyte in each sample was determined by interpo- 

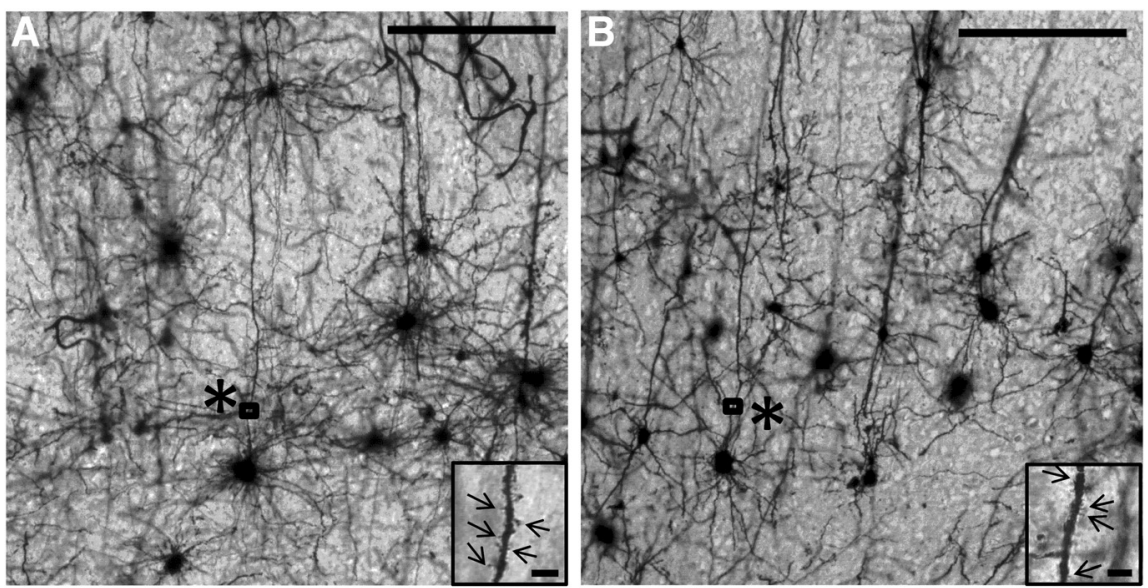

C

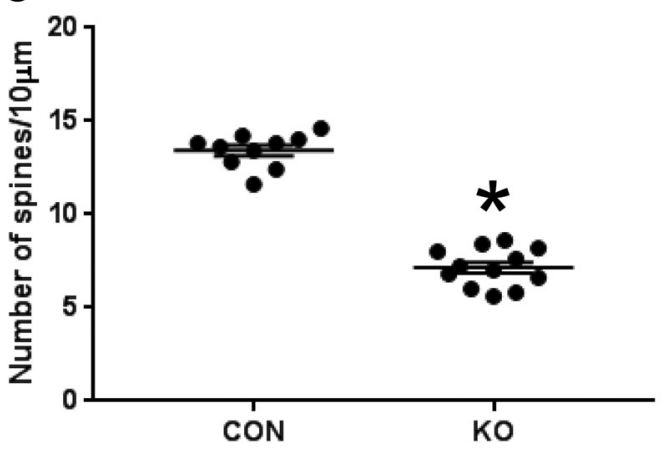

Figure 9. The number of apical dendritic spines was counted in the five continuous segments, each $10 \mu \mathrm{m}$ in length, starting at $50 \mu \mathrm{m}$ distance from the boundary between the dendrite and soma of pyramidal neurons in the cortex at PN15. A magnified view from the rectangle $\left(^{*}\right)$ is shown in the right corner. Arrows indicate spines. The number of spines was significantly reduced in the apical dendrites of KO mice $(\boldsymbol{B})$ compared with $\operatorname{CON}(\boldsymbol{A})$. C shows number of spines per $10 \mu \mathrm{m}, n=12$ neurons, $n=4$ animals (KO), $n=10$ neurons, $n=4$ animals (CON) (unpaired $t$ test, $t$ statistic [df: 20$]=14.99,{ }^{*} p<0.0001$ vs (ON). Scale bars, $200 \mu \mathrm{m}$ each. Magnified view demonstrates dendritic spines (arrows). Scale bars, $5 \mu \mathrm{m}$ each.

lation from the curves constructed from data obtained from the standard samples (ordinate, ratio of analyte peak area/internal standard peak area, abscissa, amount of analyte in each sample): a6AHA was used as the internal standard for $\mathrm{E}$ and $\mathrm{Q}$ and ${ }^{2} \mathrm{H}_{6}$-GABA was used as the internal standard for GABA. The transitions in bold font above were used for quantitation.

\section{Cortical patch-clamp study}

Coronal brain slices $(300 \mu \mathrm{m})$ from the motor cortex of PN15 mice were maintained in oxygenated artificial CSF. Cortical pyramidal neurons were recorded in voltage-clamp mode at a holding potential of $-70 \mathrm{mV}$ as described previously (Cummings et al., 2009). After 3-5 min of baseline recording, the $\mathrm{GABA}_{\mathrm{A}}$ receptor antagonist bicuculline $(5 \mu \mathrm{M})$ was applied in the bath. Data were analyzed using Clampfit 9 software (Molecular Devices) and the number of paroxysmal events and their latency were determined.

\section{Neurobehavioral tests}

SHIRPA primary screen was attempted at PN15 with modifications to suit this early age (Zhao et al., 2010). In addition, ultrasonic vocalizations were measured at PN7 and PN14 as described previously (Zhao et al., 2010).

\section{Studies in adult glut $^{\text {flox/flox/CaMK2 } \alpha-\text { Cre+ }}$ mice}

Body weight and nose-tail length

Adult body weight and nose-tail length were measured at 10 months of age in glut $^{\text {flox/flox/CaMK } 2 \alpha-\mathrm{Cre}+}(\mathrm{KO})$ versus glut $3^{\text {flox/flox }}$ mice $(\mathrm{CON})$.

Localization of Glut3 $m R N A$ in brain sections by in situ hybridization

cRNA probes. Mouse glut3 cDNA (aa 226-287 from exon 6, GenBank accession number NM_011401) was generated by RT-PCR as described previously (Shin et al., 2012). Construction of the glut 3 cRNA probes used the following glut 3 primers; 5' -gggccgtctagactgcagcgcttgtggggcacc tcgga-3' (forward with XbaI site) and $5^{\prime}$-gcg cgcgcatgcagcattgatcccagagagctgctgag- $3^{\prime}$ (reverse with SphI site). PCR products were subcloned as described previously (Shin et al., 2012). Antisense RNA probes were prepared as described previously (Shin et al., 1998, 2012). Sense probes were similarly generated with T7 RNA polymerase from the BamHI-digested cDNA fragments.

In situ hybridization histochemistry. Serial sections $(10 \mu \mathrm{m})$ from 10-month-old mice were prepared using a microtome (RM2235, Leica Microsystems). In situ hybridization was performed as described previously (Shin et al., 1998, 2012).

\section{Brain protein concentrations by immunostaining}

Coronal brain sections $(30 \mu \mathrm{m})$ from 5-monthold mice were prepared and subjected to immunofluorescence staining using goat antiCaMK2 $\alpha$ (1/50, Novus Biologicals, catalog \#N BP1-51945, RRID:AB_11037869) as a primary antibody with the corresponding secondary antibodies containing the fluorescent tag, $\mathrm{Al}$ exa Fluor 488 (Jackson ImmunoResearch Laboratories, catalog \#705-545-003, RRID: AB_2340428) as described previously (Zhao et al., 2010).

\section{Neurobehavioral studies}

SHIRPA screen. The SHIRPA Primary Screen was performed to monitor phenotypic changes in genetically modified adult mice as described previously (Zhao et al., 2010). Quantitative scoring to detect defects in gait, respiration, muscle tone, arousal, reflexes, motor control and coordination, changes in excitability and aggression, salivation, lacrimation and pilo-erection were measured (Zhao et al., 2010).

Open-field test. Assessment of anxiety, exploratory behavior, and general locomotor activity was accomplished by placing the mice in a square Plexiglas enclosure for $20 \mathrm{~min}$. Their movements were recorded by video cameras and different parameters included total distance traveled in whole arena, percentage of time spent in the center of the arena, average velocity, and resting time were measured by the associated Topscan software (Clever Sys).

Accelerating rotarod. Evaluation of motor coordination and motor learning was achieved by performing the accelerating rotarod test (RotaRod3375-5, TSE Systems). The constant speed of $5 \mathrm{rpm}$ was used at the first trial during the acquisition day. The rest of the four consecutive trials started at a beginning speed of $5 \mathrm{rpm}$ but increased by $5 \mathrm{rpm}$ after each $5 \mathrm{~s}$ up to a maximum speed of $60 \mathrm{rpm}$. Data were collected after test subject mice fell from the rod or after $300 \mathrm{~s}$ at a maximum speed of $60 \mathrm{rpm}$.

Social interaction. An interconnected three-chambered box described previously (Zhao et al., 2010) was used for evaluation of memory of interaction in subject mice. Test included three phases: habituation (phase I), assessment of sociability (phase II), and social recognition (phase III). At phase I, the subject mouse was placed in the middle chamber and allowed to explore all chambers for $10 \mathrm{~min}$. In phase II, a novel mouse (sex-matched with subject mouse) was placed inside an upsidedown wire cup in either the left or right chamber following habituation for $10 \mathrm{~min}$ on the day before testing and the other side contained an empty wire cup. The subject mouse's exploration activity and the time spent with either empty cup or the cup with novel mouse were recorded and scored by Topscan software. In phase III, a new and unfamiliar mouse was placed in the empty wire cup and the opposite side chamber 


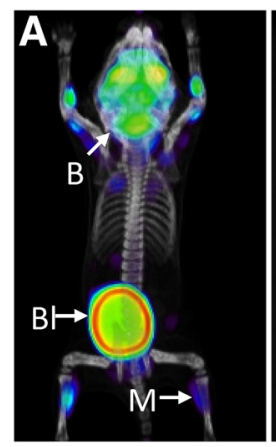

CON

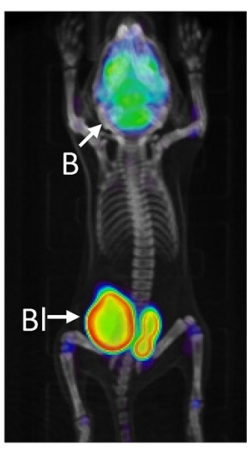

HT

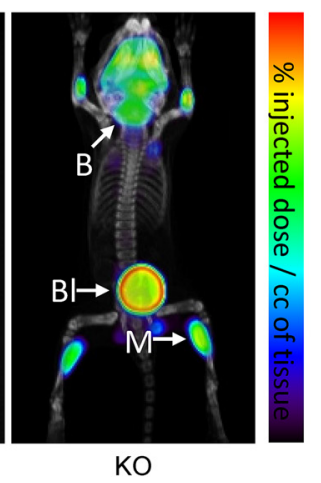

C

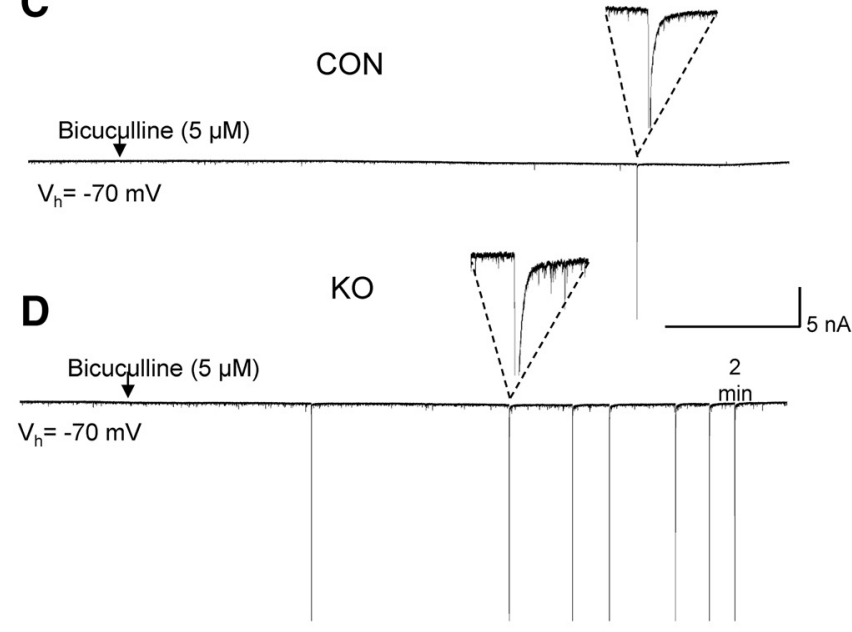

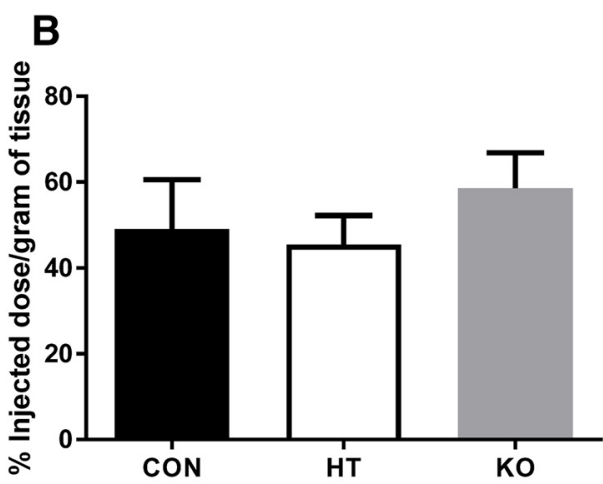

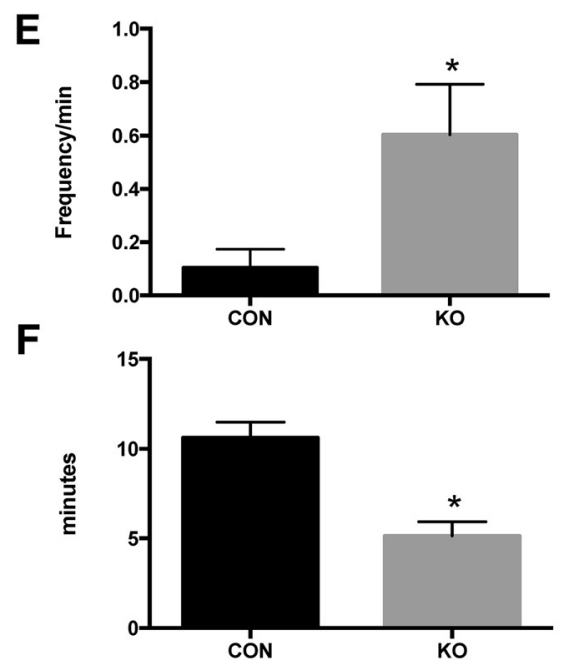

Figure 10. PET scan $(\boldsymbol{A}, \boldsymbol{B})$ and single-cell patch-clamp studies $(\boldsymbol{C}-\boldsymbol{F})$. Glucose uptake, as measured by ${ }^{18} \mathrm{~F}-\mathrm{FDG}$ accumulation in whole brain, was unaffected by Glut 3 concentrations in the brain. PN15 pups were injected intraperitoneally with $\sim 25 \mu \mathrm{Ci}$ of ${ }^{18} \mathrm{~F}-\mathrm{FDG}$. After $1 \mathrm{~h}$, the mice were imaged with PET/CT $(\boldsymbol{A})$, killed, and the amount of radioactivity in the brain was quantified on a gamma counter. B, Brain; BL, bladder; M, muscle. [ANOVA, F statistic (df: 2, 14) $=0.66$ ]. B, Representative examples of paroxysmal discharges in pyramidal neurons from CON and glut3 K0 mice at PN17. Examples of traces from $\mathrm{CON}(\boldsymbol{C})$ and glut $3 \mathrm{KO}$ pyramidal cells $(\boldsymbol{D})$. Neurons were held at $-70 \mathrm{mV}$; arrow indicates the onset of bicuculline (BIC, $5 \mu \mathrm{m}$ ) application. Insets show a detailed view of the paroxysmal events. Note that, in addition to the occurrence of more paroxysmal discharges, glut3 $\mathrm{KO}$ neurons display paroxysmal events earlier than CON neurons. Graphs represent the frequency and latency of paroxysmal activity in $\mathrm{CON}$ and $\mathrm{KO}$ mice. The total number of paroxysmal events was quantified and divided by the 15 min duration of the recording session (E). There was a significantly higher number of paroxysmal discharges in K0 mice $\left({ }^{*} p=0.0259, n=8\right.$ in both groups). Latency to the first paroxysmal discharge was also determined $(\boldsymbol{F})$. There was significantly reduced latency to the first paroxysmal event in cells from KO mice $\left({ }^{*} p=0.0037\right.$ vs CON, $n=8$ for KO and 3 for CON). Data were analyzed by unpaired Student's $t$ test and are represented as mean \pm SEM.

of the apparatus contained a familiar mouse from phase II. The time spent during the $10 \mathrm{~min}$ with the novel mouse versus the familiar mouse was compared.

Fear conditioning. For assessment of learning and memory about associated environment with aversive experiences, contextual fear conditioning was performed. At the acquisition trial, mice were placed in a chamber and received $0.75 \mathrm{~mA}$ electric foot shock 3 times within $5 \mathrm{~min}$ of conditioning in the context. Twenty-four hours after the training session, mice were returned to the context and their freezing behavior was recorded with an associated system in the absence of the associated shock (Med Associates).

Morris water maze test. The invisible platform test was performed to investigate spatial learning and memory in mice. Before the first trial, mice were initially trained to find the escaping platform $(12 \mathrm{~cm}$ diameter $)$ maintained in a constant place in a water maze pool ( $1 \mathrm{~m}$ diameter, water temperature $=24^{\circ} \mathrm{C}$ ) according to distal cues by placing the mice on the platform for $30 \mathrm{~s}$. The first training trial began after a 2 min interval. Each mouse was released in the pool from different starting quadrants that did not contain the platform. They were allowed to swim until they found the platform or when $60 \mathrm{~s}$ had elapsed. Subsequently, they were allowed to stay on the platform or placed on the platform for $5 \mathrm{~s}$. Three trials were performed per day and these trials lasted for $5 \mathrm{~d}$. The latency to find the platform was recorded for each trial. Mice were next allowed to swim for $60 \mathrm{~s}$ in the pool from the same beginning location for each mouse. Finally, they were given two consecutive visible platform trials.

\section{Experimental design and statistical analyses}

Given that our studies are novel and undertaken for the first time, we determined our sample size based on some of our prior work undertaken in classical heterozygous glut3-null mice (Ganguly et al., 2007; Zhao et al., 2010). A power analysis was performed with an expectation of a difference between the two group means of 20 with an expected SD of 10 at $80 \%$ power with a $p<0.05$. This yielded a sample size of eight/group when comparing two groups. In the case of an expected difference between means of 40 with an expected SD of 15 at $80 \%$ power and a $p<$ 0.05 , a sample size of three/group for comparing two groups proved adequate. Because our initial quantification studies did not yield genderspecific differences in postnatal studies, the genders were pooled for further analyses of the early developmental studies. Distribution of all fetal/placental and postnatal data from a mixed gender of males and females, and only males for the adult data, expressed as mean \pm SEM was determined by D'Agostino-Person or Shapiro-Wilk normality test. For Gaussian distributions, we calculated $p$-values using unpaired Student's $t$ test, whereas for non-Gaussian distributions, we used the Mann-Whitney $U$ test. Comparison between more than two groups was performed with one-way ANOVA followed by the post-hoc Fisher's PLSD test. The significance of the difference between multiple parameters was performed by two-way ANOVA followed by Sidak's or Bonferroni's post hoc analyses. Null hypothesis was rejected at a $p<0.05$. All Statistical analyses were performed using GraphPad Prism version 7 (SCR_002798). 
Table 1. SHIRPA primary screen score in CON $(n=34)$, HT $(n=19)$, and KO $(n=14)$ pups

\begin{tabular}{|c|c|c|c|c|c|c|}
\hline & \multirow[b]{2}{*}{$\mathrm{CON}$} & \multirow[b]{2}{*}{ HT } & \multirow[b]{2}{*}{ KO } & \multicolumn{3}{|l|}{$p$-value } \\
\hline & & & & (CON vs KO) & (CON vs HT) & (KO vs HT) \\
\hline \multicolumn{7}{|l|}{ Viewing jar } \\
\hline Body position & $2.70 \pm 0.12$ & $3 \pm 0$ & $2.43 \pm 0.25$ & 0.2962 & 0.5946 & $0.0377^{*}$ \\
\hline Spontaneous activity & $0.91 \pm 0.05$ & $0.95 \pm 0.05$ & $0.93 \pm 0.07$ & $>0.9999$ & $>0.9999$ & $>0.9999$ \\
\hline Respiration rate & $2 \pm 0$ & $2 \pm 0$ & $1.93 \pm 0.07$ & 0.1993 & $>0.9999$ & 0.2914 \\
\hline Tremor & $0 \pm 0$ & $0 \pm 0$ & $0 \pm 0$ & 1 & 1 & 1 \\
\hline Urination & $0.059 \pm 0.04$ & $0.053 \pm 0.05$ & $0 \pm 0$ & $>0.9999$ & $>0.9999$ & $>0.9999$ \\
\hline Defecation & $0.09 \pm 0.06$ & $0.16 \pm 0.12$ & $0.5 \pm 0.2$ & 0.0412 & $>0.9999$ & 0.1867 \\
\hline \multicolumn{7}{|l|}{ Arena } \\
\hline Transfer arousal & $3.68 \pm 0.19$ & $4 \pm 0.23$ & $3.5 \pm 0.34$ & $>0.9999$ & 0.9389 & 0.6174 \\
\hline Locomotor activity & $3.38 \pm 0.57$ & $3.89 \pm 0.59$ & $2.57 \pm 0.72$ & $>0.9999$ & $>0.9999$ & 0.6535 \\
\hline Palpebral closure & $1.06 \pm 0.04$ & $1 \pm 0$ & $1.07 \pm 0.13$ & $>0.9999$ & $>0.9999$ & $>0.9999$ \\
\hline Piloerection & $0 \pm 0$ & $0 \pm 0$ & $0 \pm 0$ & 1 & 1 & 1 \\
\hline Startle response & $0 \pm 0$ & $0 \pm 0$ & $0 \pm 0$ & 1 & 1 & 1 \\
\hline Gait & $0.68 \pm 0.16$ & $0.37 \pm 0.21$ & $1 \pm 0.3$ & 0.8883 & 0.8109 & 0.205 \\
\hline Pelvic elevation & $1.94 \pm 0.04$ & $2 \pm 0$ & $2 \pm 0.1$ & $>0.9999$ & $>0.9999$ & $>0.9999$ \\
\hline Tail elevation & $1 \pm 0$ & $1 \pm 0$ & $1 \pm 0$ & 1 & 1 & 1 \\
\hline Touch escape & $1.06 \pm 0.04$ & $1 \pm 0$ & $1.07 \pm 0.07$ & $>0.9999$ & 0.9924 & $>0.9999$ \\
\hline Positional passivity & $0 \pm 0$ & $0 \pm 0$ & $0 \pm 0$ & 1 & 1 & 1 \\
\hline Trunk curl & $1 \pm 0$ & $1 \pm 0$ & $1 \pm 0$ & 1 & 1 & 1 \\
\hline Limb grasping & $1 \pm 0$ & $1 \pm 0$ & $1 \pm 0$ & 1 & 1 & 1 \\
\hline Whisker brush & $1.88 \pm 0.06$ & $2 \pm 0$ & $1.93 \pm 0.07$ & $>0.9999$ & 0.3737 & $>0.9999$ \\
\hline \multicolumn{7}{|l|}{ Above arena } \\
\hline Abnormal behavior & $1 \pm 0$ & $1 \pm 0$ & $1 \pm 0$ & 1 & 1 & 1 \\
\hline Visual placing & $1.91 \pm 0.05$ & $1.68 \pm 0.11$ & $1.64 \pm 0.13$ & 0.1094 & 0.1478 & $>0.9999$ \\
\hline Grip strength & $1.70 \pm 0.08$ & $1.68 \pm 0.11$ & $1.21 \pm 0.11$ & $0.0039^{*}$ & $>0.9999$ & $0.0152^{*}$ \\
\hline Wire manoeuvre & $2.38 \pm 0.12$ & $2.16 \pm 0.09$ & $3 \pm 0.23$ & $0.0148^{*}$ & 0.7352 & $0.002^{*}$ \\
\hline Body tone & $1 \pm 0$ & $1 \pm 0$ & $1 \pm 0$ & 1 & 1 & 1 \\
\hline Pinna reflex & $0.38 \pm 0.08$ & $0.47 \pm 0.12$ & $0.35 \pm 0.13$ & $>0.9999$ & $>0.9999$ & $>0.9999$ \\
\hline Corneal reflex & $0.91 \pm 0.05$ & $0.95 \pm 0.05$ & $0.78 \pm 0.11$ & 0.6029 & $>0.9999$ & 0.4203 \\
\hline Toe pinch & $1.15 \pm 0.15$ & $1.26 \pm 0.15$ & $1.21 \pm 0.19$ & $>0.9999$ & $>0.9999$ & $>0.9999$ \\
\hline \multicolumn{7}{|l|}{ Supine restraint } \\
\hline Body length & $5.46 \pm 0.07$ & $5.25 \pm 0.08$ & $4.79 \pm 0.12$ & $<0.0001^{*}$ & 0.172 & $0.0049^{*}$ \\
\hline Skin color & $1 \pm 0$ & $1 \pm 0$ & $1 \pm 0$ & 1 & 1 & 1 \\
\hline Limb tone & $1 \pm 0$ & $1 \pm 0$ & $1 \pm 0$ & 1 & 1 & 1 \\
\hline Lacrimation & $0.06 \pm 0.04$ & $0 \pm 0$ & $0 \pm 0$ & 0.8524 & 0.7066 & $>0.9999$ \\
\hline Salivation & $0 \pm 0$ & $0 \pm 0$ & $0 \pm 0$ & 1 & 1 & 1 \\
\hline Provoked biting & $0.44 \pm 0$ & $0.31 \pm 0.11$ & $0.28 \pm 0.13$ & 0.9635 & $>0.9999$ & $>0.9999$ \\
\hline Righting reflex & $0.20 \pm 0.07$ & $0.16 \pm 0.09$ & $0.5 \pm 0.14$ & 0.0995 & $>0.9999$ & 0.0773 \\
\hline Contact righting & $1 \pm 0$ & $1 \pm 0$ & $1 \pm 0$ & 1 & 1 & 1 \\
\hline Negative geotaxis & $2.53 \pm 0.31$ & $1.89 \pm 0.45$ & $2.86 \pm 0.5$ & $>0.9999$ & 0.7093 & 0.4363 \\
\hline Fear & $0 \pm 0$ & $0 \pm 0$ & $0 \pm 0$ & 1 & 1 & 1 \\
\hline Irritability & $0.97 \pm 0.03$ & $0.89 \pm 0.07$ & $1 \pm 0$ & $>0.9999$ & 0.6206 & 0.465 \\
\hline Aggression & $0.41 \pm 0.09$ & $0.26 \pm 0.1$ & $0.28 \pm 0.13$ & $>0.9999$ & 0.8529 & $>0.9999$ \\
\hline Vocalization & $0.03 \pm 0.03$ & $0 \pm 0$ & $0 \pm 0$ & $>0.9999$ & $>0.9999$ & $>0.9999$ \\
\hline Body weight & $5.92 \pm 0.12$ & $5.31 \pm 0.11$ & $4.58 \pm 0.2$ & $<0.0001^{*}$ & $0.0064^{*}$ & $0.0067^{*}$ \\
\hline
\end{tabular}

*Significant difference among the groups as analyzed by one-way ANOVA followed by Bonferroni's multiple-comparisons test.

\section{Results}

Two conditional glut3 KO mouse lines were successfully created

In our present study, conditional glut3 $\mathrm{KO}$ mouse lines were successfully created by the Cre/LoxP recombination system designed to delete Exon 6 (Fig. 1) and create a distal frame shift. The expression of Nestin protein was investigated in early-stage WT brain tissue at E13.5 (Fig. 2A,B), whereas the expression of CaMK $2 \alpha$ protein was detected in adult brain alone (Tsien et al., 1996) (Fig. 2C,E), but not in $18 \mathrm{~d}$ gestation placenta (Fig. 2D,F). Therefore, glut $3^{\text {flox/flox/nestin-Cre+ }}$ mice expressed an early life postnatal phenotype, whereas the glut $3^{\text {flox/flox/CaMK } 2 \alpha-\mathrm{Cre}+}$ expressed a later life adult phenotype. In our present study, glut $3^{\text {flox/llox }}$ is referred to as glut $3^{+/+}$ (CON), glut $3^{\text {flox } /+/ \text { Cre }+}$ as glut $3^{+l-}$ (HT), and glut $3^{\text {flox/flox } / \mathrm{Cre}+}$ as glut3 $3^{-1-}(\mathrm{KO})$. The glut $3^{\text {flox/flox/nestin-Cre+ }}\left(\right.$ glut $\left.^{-1-}\right)$ genotype demonstrates a postnatal phenotype.
The body weight of glut $3^{-1-}(\mathrm{KO})$ mice was not different at PN10, declining by PN14 and PN15 as depicted in growth curves (Fig. 3A) compared with glut $3^{+/+} \mathrm{CON}$ and glut $3^{+/-}$ HT. In addition, glut $3 \mathrm{KO}$ mice had a reduced nose-rump length at PN15 compared with CON and HT mice (Fig. 3B). Survival curves demonstrated a difference between the three genotypes, with KO showing early demise between PN15 and PN31 (Fig. 3C). Introduction of a ketogenic diet during E15E21 of prenatal development and through postnatal life failed to rescue $\mathrm{KO}$ mice. No major change occurred, although a trend for higher body weights of the glut $3 \mathrm{KO}$ mice $(5.4 \pm 0.0 \mathrm{~g}$ at $\mathrm{PN} 15)$ was observed compared with those raised on a regular chow diet $(4.6 \pm 0.11 \mathrm{~g}$ at $\mathrm{PN} 15, p=0.16)$. Glut3 $\mathrm{KO}$ pups in both diet groups were either found dead or cannibalized by dams and presumed dead.

Although blood glucose at the basal state did not show a significant difference at PN15 (Fig. 3D, top), it trended lower 
A

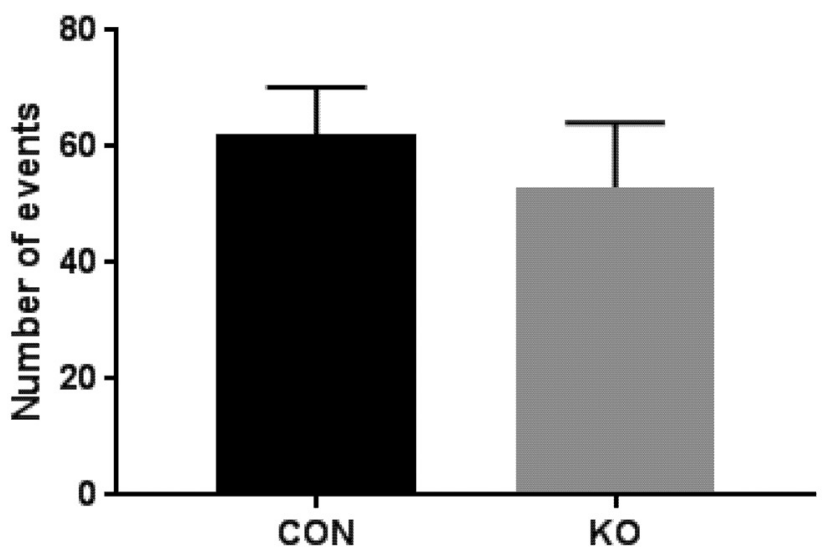

C

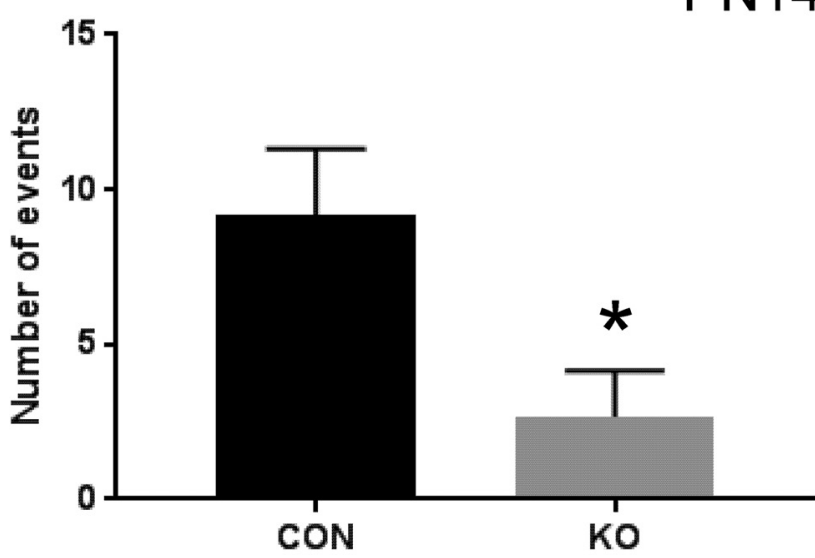

B

PN7

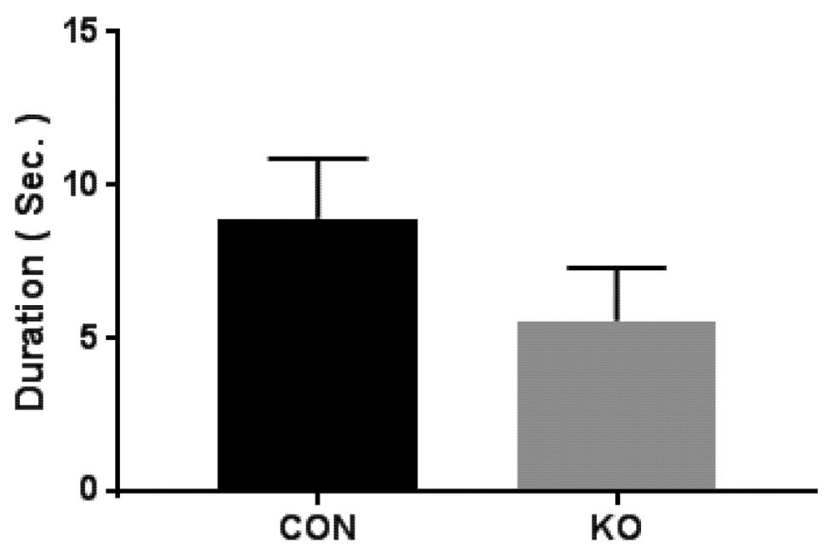

D

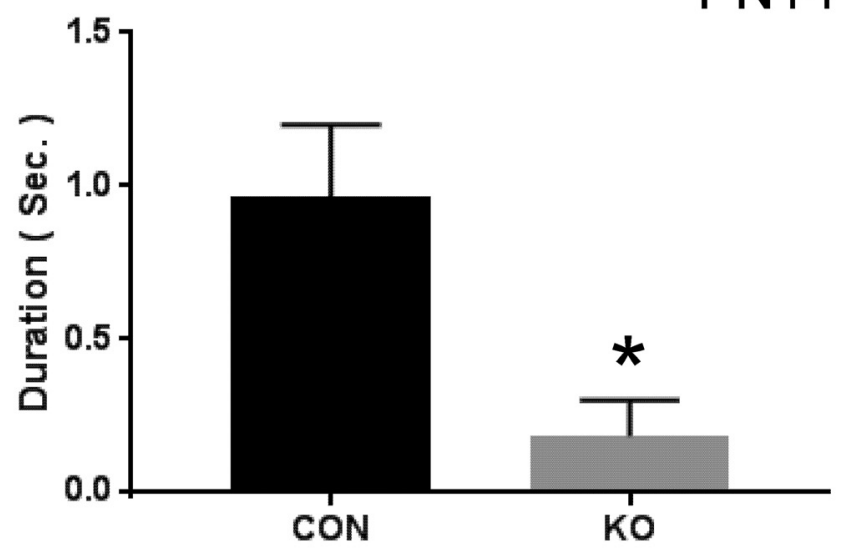

Figure 11. $\quad \boldsymbol{A}, \boldsymbol{B}$, Vocalization at PN7. There are no significant differences in the number of events $(\boldsymbol{A})$ and total duration $(\boldsymbol{B})$ among CON and K0 groups (Mann-Whitney rank-sum test: $\boldsymbol{A}, U$ statistics $=344.5, p$-value $=0.975 ; \boldsymbol{B}$, U statistics $=372, p=0.640) . \boldsymbol{C}, \boldsymbol{D}$, Vocalization at PN14. K0 demonstrated a significant decrease in the number of events $(\boldsymbol{C})$ and total duration $(\boldsymbol{D})$ among CON and K0 groups (Mann-Whitney rank-sum test: $C$, U statistics $=142,{ }^{*} p$-value $=0.042 ; D$, U statistics $=154,{ }^{*} p=0.013$ ). PN7: $n=12$ for K0, $n=57$ for CON; PN14, $n=6$ for K0, $n=31$ for CON.

in glut3 $\mathrm{KO}$ versus $\mathrm{HT}$ and CON; however, at PN21, a significant decrease was observed (Fig. 3D, bottom). Brain weights of PN15 glut3 KO mice were also reduced compared with CON or HT mice (Fig. 3E). To determine the contributing factor leading to reduction in body and brain weights and noserump length, caloric intake was measured and found to be increased at PN15 in both the glut3 $\mathrm{KO}$ and HT mice versus CON (Fig. $3 F$ ), eliminating the theory that loss of brain Glut3 interfered with the feeding ability of these mice. If anything, there was an increase in $\mathrm{KO}$ versus $\mathrm{CON}$, suggesting the possibility of matching increased energy expenditure generally found with stunting (Dai et al., 2012; Shin et al., 2012). Attempts were made to measure energy expenditure by indirect calorimetry as described previously by us (Dai et al., 2012; Shin et al., 2012); however, the small size of KO mice precluded accurate determinations. At PN21, however, no milk was recovered from the stomach, suggesting a reduced intake by this preterminal stage.

We assessed CON tissues that expressed Glut3 at PN15 and noted that the brain and testis were the only two tissues with significant amounts of Glut3 (data not shown). Our further studies therefore focused mainly on brain, retina, and testis, but also on the placenta that previously demonstrated Glut3 expression (Ganguly et al., 2007).

In the E18 placenta, Glut1 protein was expressed in the junctional region and the labyrinth, whereas Glut3 protein was also expressed in the labyrinth, with no observed difference in the expression of Glut 1 and Glut3 proteins in this region between $\mathrm{CON}$ and $\mathrm{KO}$ (Fig. $4 A-H$ ). This observation bore out in Western blots, where quantification also revealed no difference between CON and KO E18 placental Glut1 and Glut3 proteins (Fig. 4I). In addition, we assessed intraplacental and trans-placental glucose transport and observed no intergenotype differences (Fig. $4 J$ ) and no significant change in placental weights $(\mathrm{CON}=0.074 \pm 0.0006 \mathrm{~g}[n=9]$ vs $\mathrm{KO}=$ $0.08 \pm 0.004 \mathrm{~g}[n=10])$. Specifically, localization of Glut3 was observed in syncytiotrophoblasts lining the maternal vascular space, whereas Nestin was noted in endothelial cells lining the fetal capillary space (Fig. $4 K-N$ ). In addition, the expression of Nestin in endothelial cells was confirmed by colocalization with an endothelial cell marker, CD34 (Fig. 5A-C). This cell-specific differential expression of Nestin and Glut3 was responsible for not abolishing placental glut3 expression in $\mathrm{KO}$ mice. This provided a murine model that disconnected the presenting phenotype of the $\mathrm{KO}$ offspring from 
CON
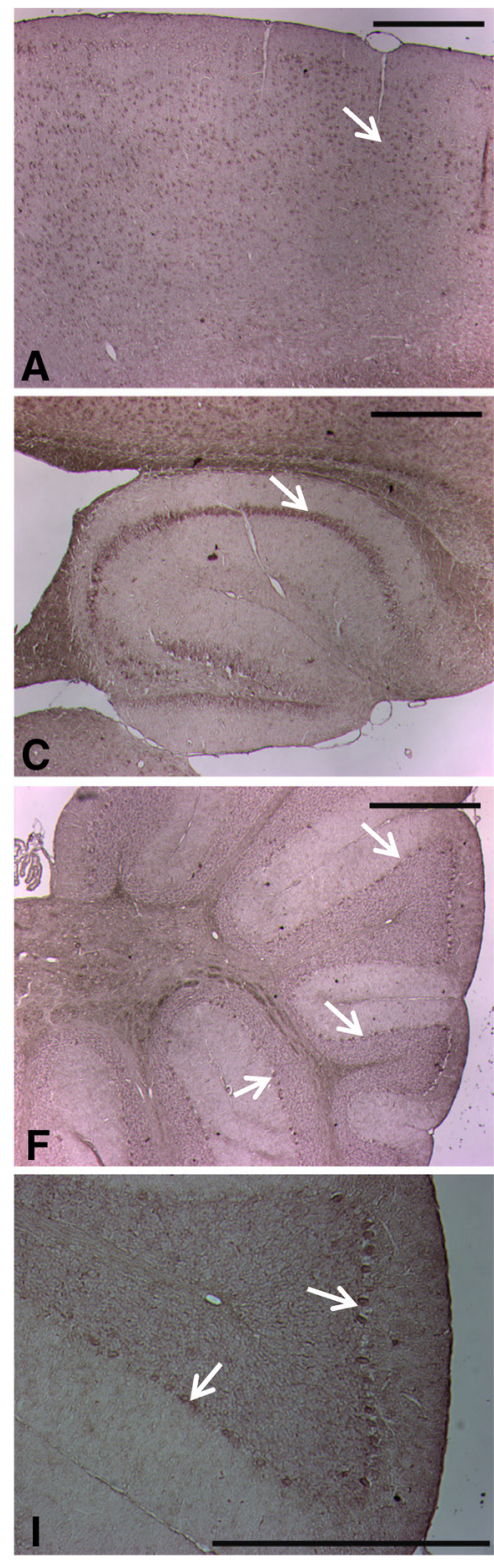

$\mathrm{KO}$
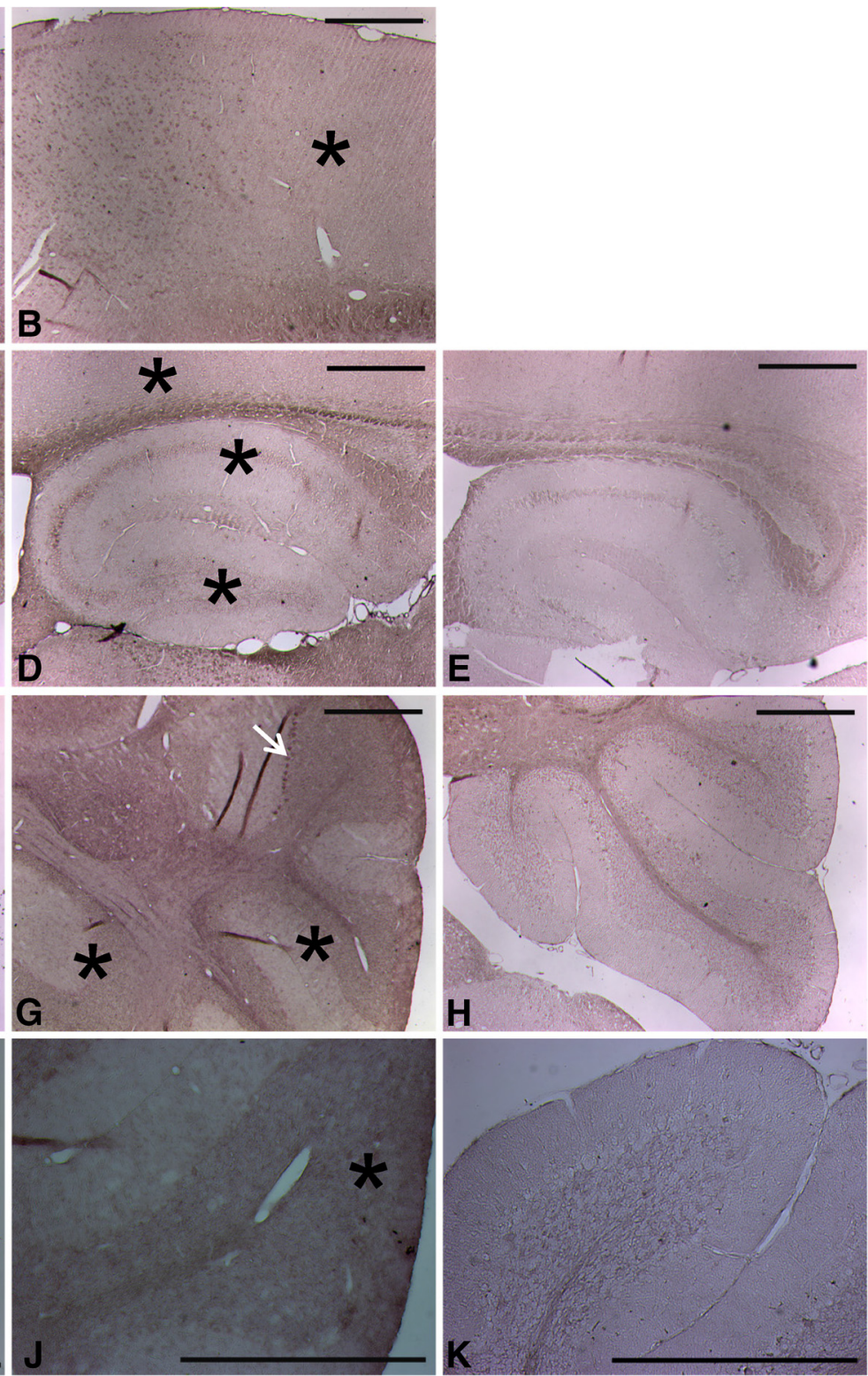
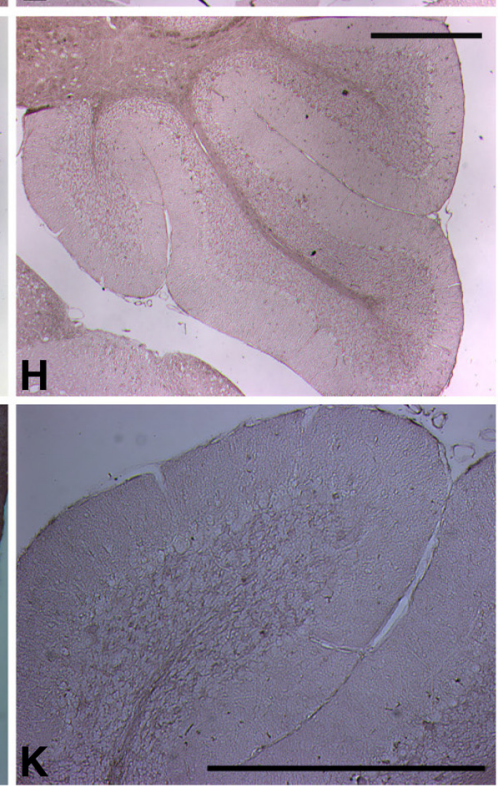

Figure 12. In situ hybridization histochemistry of glut 3 gene expression in adult mouse brain. After overnight incubation with DIG-labeled riboprobes targeting exon 6 of the $g$ lut 3 gene, alkaline phosphatase-conjugated sheep anti-DIG IgG antibody (Roche Applied Science) was used for color development. In CON $(A, C, F, I)$, antisense probes show positive signals (arrows) in the neuronal cells of cortex, hippocampus, and cerebellum. In $\mathrm{KO}(\boldsymbol{B}, \boldsymbol{D}, \mathbf{G}, \boldsymbol{J})$, antisense probes show significantly reduced immunoreactivity including within the parietal cortical association and retrosplenial agranular cortex $(\boldsymbol{B}), C A 1$ and dentate gyrus region of hippocampus $(\boldsymbol{D})$, and cerebellar lobule $(\boldsymbol{G}, \boldsymbol{J})$. Controls with the corresponding sense RNA probes show the immunoreactivity completely abolished $(\boldsymbol{E}, \boldsymbol{H}, \boldsymbol{K})$. Asterisks indicate reduced immunoreactivity in $\boldsymbol{B}, \boldsymbol{D}, \mathbf{G}$, and $\boldsymbol{J}$. Scale bars, $500 \mu \mathrm{m}$.

changes in placental Glut3 protein concentrations as encountered in the classical glut3-null heterozygous mouse (Ganguly et al., 2007).

In the case of brain with developmentally early expression of Nestin, the expression of the glut3 gene was significantly decreased ( 49 to $54 \%$ ), whereas there was no difference in Glut1 protein concentrations in brains of E18 glut $3 \mathrm{KO}$ compared with CON (Fig. 6A). Fetal brain (E18) glucose uptake (nmol/mg/min) was not reduced in $\mathrm{KO}$ versus $\mathrm{CON}(\mathrm{CON}=6040 \pm 841[n=9]$ vs $\mathrm{KO}=6954 \pm 1846[n=10])$, reflecting the unchanged Glut1 rather than the reduced Glut3 protein concentration in KO. Additionally, there was no difference in fetal body weights $(\mathrm{CON}=$ $1.03 \pm 0.03 \mathrm{~g}[n=9]$ vs $\mathrm{KO}=1.07 \pm 0.02 \mathrm{~g}[n=10])$. Again, postnatally at $\mathrm{PN} 1$, immunofluorescence localization revealed both Glut1 and Glut3 proteins, with no difference in Glut1 pro- tein between the two genotypes (Fig. $6 B, C$ ). In contrast, Glut3 protein was decreased in glut3 $\mathrm{KO}$ compared with CON (Fig. $6 D, E)$. Colocalization experiments of Glut1 with Glut3 are also depicted (Fig. 6F,G). This reduction in brain Glut3 concentration was not associated with changes in body or brain weights and body length until PN14 (Fig. $3 A, B, E$ ). However, at PN15, when stunting was observed (Fig. $3 A, B, E$ ), Western blots revealed a dramatic $80.5 \%$ reduction in brain Glut3 protein concentrations in glut $3 \mathrm{KO}$ versus $\mathrm{CON}$, whereas brain Glut1 protein concentrations remained unchanged (Fig. $6 H$ ). Immunohistochemical analysis (Fig. 6I-N) also revealed a dramatic reduction in Glut3 immunoreactivity in PN15 glut3 KO cerebral cortex (Fig. 6J), hippocampus (Fig. 6L), and cerebellum (Fig. $6 N$ ) versus the agematched CON (Fig. 6I, K,M). Examination of testes revealed a 
A

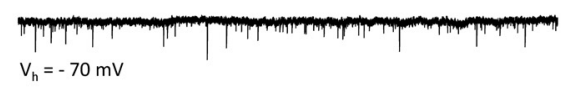

KO

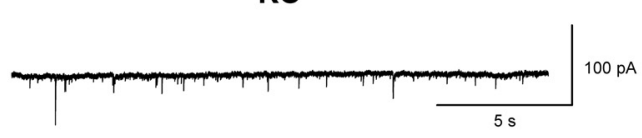

B

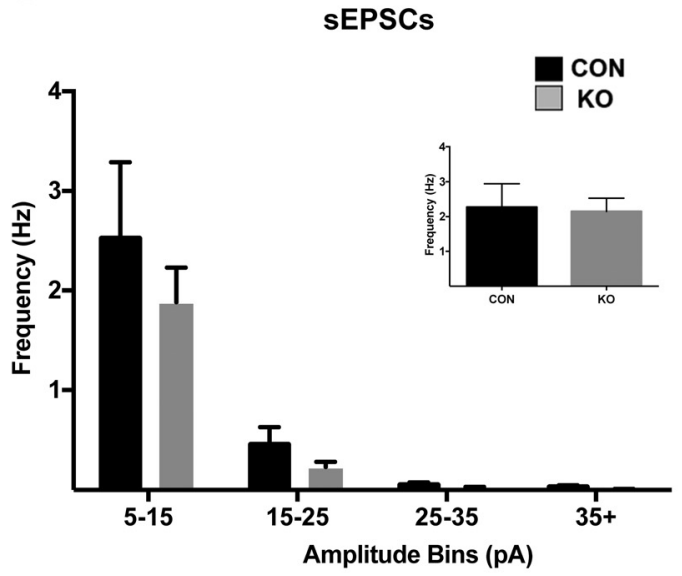

C

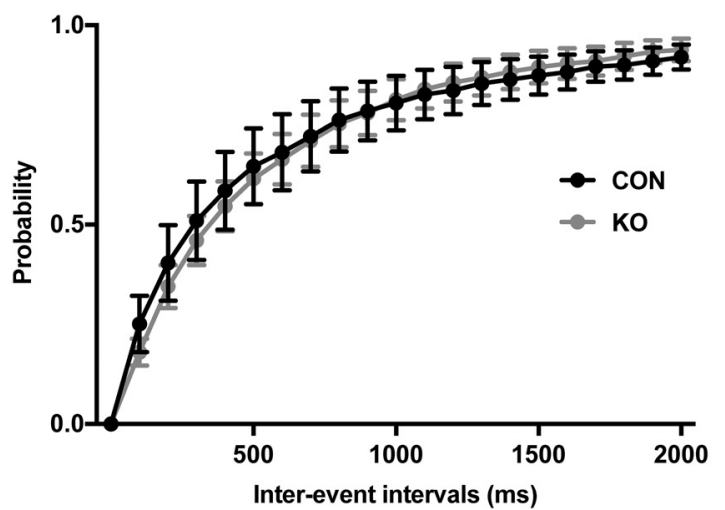

CON
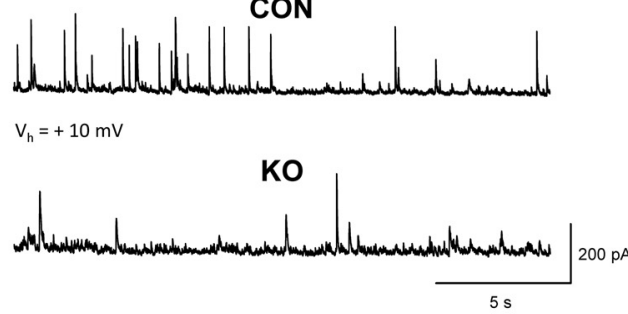

SIPSCs
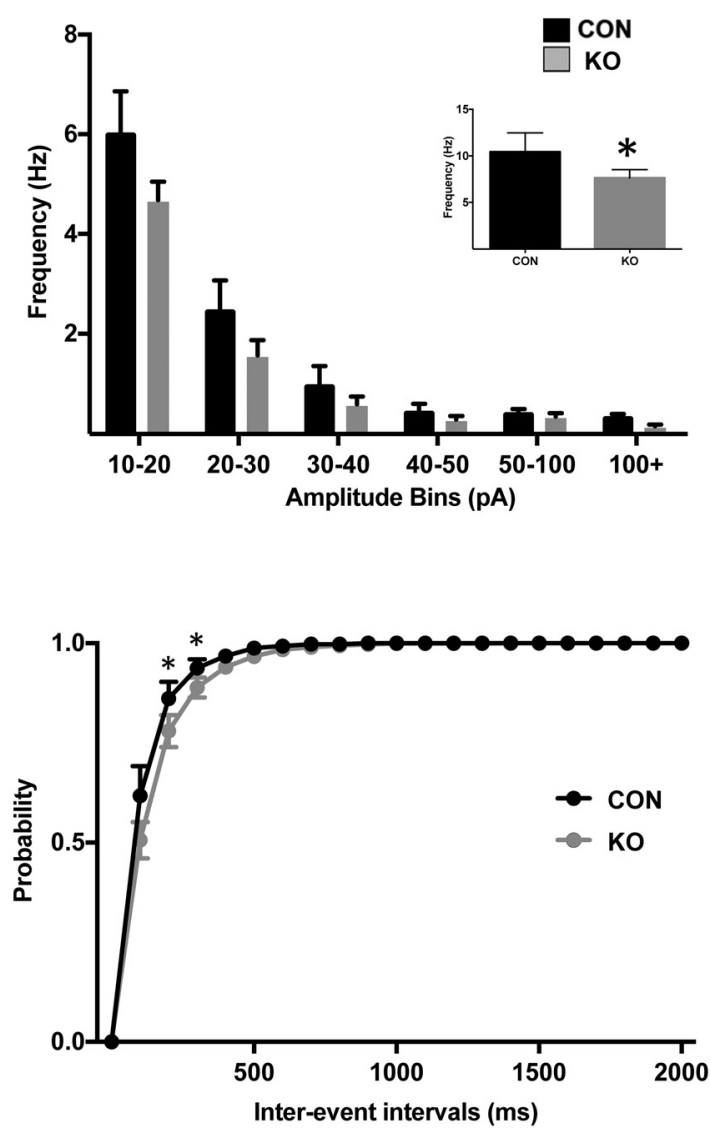

Figure 13. A, Representative traces of SEPSCS (left) and sIPSCs (right) in a pyramidal neuron from CON and K0 mice at holding potentials $\left(V_{\mathrm{h}}\right)$ of $-70 \mathrm{mV}$ and $+10 \mathrm{mV}$, respectively. $\boldsymbol{B}$, Amplitude-frequency histograms for sEPSCS (left) and sIPSCs (right) in CON and KO neurons. No significant changes in either sEPSCs or sIPSCs frequencies at different amplitude bins were observed between CON and KO neurons. Insets show the average frequency of SEPSCS (left) and sIPSCs (right). Although no significant change in average frequency was observed in SEPSCS, KO pyramidal neurons showed a significant decrease in sIPSC average frequency relative to CON neurons. Amplitude-frequency histogram data were analyzed by two-way ANOVA followed by Bonferroni's multiple-comparisons test. Average frequency data shown in graphs were analyzed by unpaired Student's $t$ test, ${ }^{*} p=0.04$. C, Cumulative interevent interval histograms for sEPSCs (left) and sIPSCs (right). Although no significant change was observed for sEPSC cumulative interevent interval histograms, for sIPSCS, the K0 group was shifted to the right, and the difference between $\mathrm{CON}$ and $\mathrm{KO}$ groups was significantly different for the $300-400 \mathrm{~ms}$ bins indicating decreased frequency of sIPSCs. Data were analyzed by two-way ANOVA followed by Bonferroni's multiple-comparisons test, $n=10$ neurons for $\mathrm{K} 0, n=8$ neurons for CON, ${ }^{*} p<0.05$.

reduction in Glut3 immunoreactivity within the spermatid of the glut $\mathrm{KO}$ mice compared with $\mathrm{CON}$ (Fig. $7 A, B$ ). These findings attested to the success of creating faithful conditional glut3 $\mathrm{KO}$ mouse lines.

Based on these findings, we confirmed changes with immunofluorescent histochemistry (Fig. $8 A-F$ ). Synaptophysin (Fig. $8 A, D)$ and Map2 (Fig. $8 B, E$ ) were decreased in $\mathrm{KO}$ (Fig. $8 D-F$ ) compared with CON (Fig. $8 A-C$ ). We further investigated cellspecific markers in PN15 brains by Western blots and detected a trend in reduction of synaptophysin (neuronal/axonal marker), Map2 (neuronal/dendritic marker), and tubulin proteins in $\mathrm{KO}$ brains compared with CON (Fig. 8G). We next assessed compensatory changes in response to reduced PN15 brain Glut3 protein concentrations. We noted no difference in brain Glut 4 or Glut8 protein concentrations between $\mathrm{KO}$ and $\mathrm{CON}$ mice. Again, no difference was seen with MCT2 despite a trending increase evident by Western blot analysis (Fig. $8 H$ ). Glut1 protein was also expressed with the same intensity within the retinal pigmented epithelium (Fig. 8I, J, arrows) of PN15 eyes in both CON (Fig. 8I) and $\mathrm{KO}$ (Fig. 8J) genotypes. In contrast, Glut3 immunoreactivity was reduced in the KO retinal inner plexiform layer (Fig. $8 \mathrm{~L}$ ) compared with $\mathrm{CON}$ (Fig. $8 \mathrm{~K}$ ), with 
associated structural disruption (Fig. $8 I, K, M$ in CON; Fig. $8 J, L, N)$ seen in $\mathrm{KO}$.

These observations prompted further assessments of neuronal cells. The number $(\mathrm{KO}=2.83 \pm 0.54, n=6$, vs $\mathrm{CON}=$ $2.71 \pm 0.42, n=7 ; p=0.67)$ and length $(\mathrm{KO}=55.85 \pm 9.94 \mu \mathrm{m}$, $n=6$, vs $C O N=61.76 \pm 10.79 \mu \mathrm{m}, n=7 ; p=0.74)$ of secondary dendritic branches in pyramidal neurons of the cortex were no different between the genotypes. The number of apical dendritic spines in pyramidal neurons of the cortex was, however, significantly reduced in $\mathrm{KO}$ mice (Fig. $9 A-C$ ). These findings were associated with diminished cerebral cortical thickness in $\mathrm{KO}$ versus CON brains, as assessed with hematoxylin and eosinstained morphological measurements $(\mathrm{KO}=864.3 \pm 13.87 \mu \mathrm{m}$ $[n=73]$ vs $\mathrm{CON}=970.2 \pm 17.15 \mu \mathrm{m}[n=87], p<0.001)$.

\section{Absence of postnatal brain Glut 3 is associated with functional and behavioral changes}

PET scanning at PN15 revealed no significant change in brain ${ }^{18} \mathrm{~F}-\mathrm{FDG}$ uptake despite an almost lack of Glut3 protein in brain at this postnatal age (Fig. $10 A, B$ ). The ${ }^{18} \mathrm{~F}$-DG uptake appeared to reflect the brain Glut1 protein concentrations, which remained unchanged in the two genotypes. We also measured amino acids in brain such as glutamate and GABA. There was no significant difference in $\mathrm{KO}$ compared with $\mathrm{CON}$ (glutamic acid, $\mathrm{KO} 45341 \pm 3173 \mathrm{pmol}$, CON $50953 \pm 1722 \mathrm{pmol}, p=0.1190$; glutamine, KO $51098 \pm 5127$ pmol, CON $52749 \pm 2025$ pmol, $p=0.7542 ; \mathrm{GABA}, \mathrm{KO} 12749 \pm 546.5 \mathrm{pmol}, \mathrm{CON} 13691 \pm 523.8$ pmol, $p=0.2264, n=12[\mathrm{KO}]$ and $n=14[\mathrm{CON}]$ for each neuropeptide). We next used single-cell patch-clamp recordings of cortical pyramidal neurons in slices (Fig. 10C-F) and observed that the passive membrane properties (membrane capacitance, input resistance, and time constant) were similar in $\mathrm{KO}$ and $\mathrm{CON}$ cells. Similarly, no significant differences were found in spontaneous glutamatergic $(\mathrm{V}$ hold $=-70 \mathrm{mV})$ or GABAergic $(\mathrm{V}$ hold $=+10 \mathrm{mV}$ ) activities. However, after bath application of bicuculline to block $\mathrm{GABA}_{\mathrm{A}}$ receptors, pyramidal neurons displayed paroxysmal discharges consisting of large inward currents and bursts of spontaneous glutamate activity. The number of paroxysmal discharges was significantly increased, whereas the latency to first discharge was decreased in neurons from $\mathrm{KO}$ mice compared with CON (Fig. 10E,F; for examples of paroxysmal discharges in a WT and KO neuron, see Fig. 10C,D). These findings suggested increased cortical excitability after $\mathrm{GABA}_{\mathrm{A}}$ receptor block and could partially explain the reduced number of dendritic spines in pyramidal neurons.

SHIRPA testing of glut $^{\text {flox/flox/nestin-Cre+ }}$ mice revealed an early postnatal phenotype. KO mice displayed increased aggression, provoked biting, and righting reflex, whereas palpebral closure and negative geotaxis showed a downward slope in PN15 KO mice versus CON (Table 1). In addition, although ultrasonic vocalizations were not different at PN7 (Fig. 11 $A, B$ ), they were significantly reduced at PN14 (Fig. 11C,D), similar to findings in mouse models of autism spectrum disorders (Zhao et al., 2010; Wöhr et al., 2011; Roy et al., 2012).

\section{glut $^{\text {flox/flox/CaMK2 } \alpha \text {-Cre+ }}$ (glut3 KO) genotype expresses a late adult phenotype}

Given that the glut $3^{\text {flox/flox/nestin-Cre+ }}$ mice displayed significant stunting and shortened lifespan, characterization of the adult phenotype was precluded. Therefore, it was imperative to create additional mouse lines carrying glut 3 gene deletions in
Table 2. SHIRPA primary screen score in CON $(n=22)$ and KO $(n=21)$ adult mice

\begin{tabular}{|c|c|c|c|}
\hline & $\mathrm{CON}$ & KO & $\overline{p \text {-value }}$ \\
\hline \multicolumn{4}{|l|}{ Viewing jar } \\
\hline Body position & $3 \pm 0$ & $3 \pm 0$ & 1.0000 \\
\hline Spontaneous activity & $1.22 \pm 0.09$ & $1.23 \pm 0.09$ & 0.9208 \\
\hline Respiration rate & $2.09 \pm 0.06$ & $2.04 \pm 0.05$ & 0.5869 \\
\hline Tremor & $0 \pm 0$ & $0 \pm 0$ & 1.0000 \\
\hline Urination & $0.045 \pm 0.04$ & $0.09 \pm 0.06$ & 0.5358 \\
\hline Defecation & $1.45 \pm 0.29$ & $1.66 \pm 0.4$ & 0.6736 \\
\hline \multicolumn{4}{|l|}{ Arena } \\
\hline Transfer arousal & $4.86 \pm 0.07$ & $5 \pm 0$ & 0.0829 \\
\hline Locomotor activity & $26.45 \pm 1.27$ & $23.04 \pm 0.94$ & $0.0387^{*}$ \\
\hline Palpebral closure & $0 \pm 0$ & $0 \pm 0$ & 0.0990 \\
\hline Piloerection & $0 \pm 0$ & $0 \pm 0$ & 1.0000 \\
\hline Startle response & $0.68 \pm 0.1$ & $0.42 \pm 0.11$ & 0.0990 \\
\hline Gait & $0 \pm 0$ & $0 \pm 0$ & 1.0000 \\
\hline Pelvic elevation & $2 \pm 0$ & $2 \pm 0$ & 1.0000 \\
\hline Tail elevation & $1.04 \pm 0.04$ & $1.14 \pm 0.1$ & 0.3884 \\
\hline Touch escape & $1.59 \pm 0.16$ & $1.47 \pm 0.16$ & 0.6129 \\
\hline Positional passivity & $0 \pm 0$ & $0 \pm 0$ & 1.0000 \\
\hline Trunk curl & $1 \pm 0$ & $1 \pm 0$ & 1.0000 \\
\hline Limb grasping & $1 \pm 0$ & $1 \pm 0$ & 1.0000 \\
\hline Whisker brush & $2.14 \pm 0.14$ & $2 \pm 0$ & 0.1985 \\
\hline \multicolumn{4}{|l|}{ Above arena } \\
\hline Abnormal behavior & $0.36 \pm 0.10$ & $0.42 \pm 0.11$ & 0.6736 \\
\hline Visual placing & $3.13 \pm 0.13$ & $2.71 \pm 0.14$ & $0.0370^{*}$ \\
\hline Grip strength & $2 \pm 0.14$ & $1.61 \pm 0.11$ & $0.0449^{*}$ \\
\hline Wire maneuver & $1.18 \pm 0.21$ & $2 \pm 0.23$ & $0.0146^{*}$ \\
\hline Body tone & $1.36 \pm 0.1$ & $1.09 \pm 0.06$ & $0.0379^{*}$ \\
\hline Pinna reflex & $1.22 \pm 0.09$ & $1.04 \pm 0.04$ & 0.0934 \\
\hline Corneal reflex & $1 \pm 0$ & $1 \pm 0$ & 1.0000 \\
\hline Toe pinch & $2.95 \pm 0.07$ & $2.95 \pm 0.04$ & 1.0000 \\
\hline \multicolumn{4}{|l|}{ Supine restraint } \\
\hline Body length & $9.81 \pm 0.11$ & $9.75 \pm 0.12$ & 0.8077 \\
\hline Skin color & $1 \pm 0$ & $1 \pm 0$ & 1.0000 \\
\hline Limb tone & $1.63 \pm 0.1$ & $1.4 \pm 0.11$ & 0.1316 \\
\hline Lacrimation & $0 \pm 0$ & $0 \pm 0$ & 1.0000 \\
\hline Salivation & $0 \pm 0$ & $0 \pm 0$ & 1.0000 \\
\hline Provoked biting & $1 \pm 0$ & $0.95 \pm 0.05$ & 0.3006 \\
\hline Righting reflex & $0 \pm 0$ & $0 \pm 0$ & 1.0000 \\
\hline Contact righting & $1 \pm 0$ & $1 \pm 0$ & 1.0000 \\
\hline Negative geotaxis & $0.09 \pm 0.09$ & $0.4 \pm 0.18$ & 0.1284 \\
\hline Fear & $0 \pm 0$ & $0 \pm 0$ & 1.0000 \\
\hline Irritability & $1 \pm 0$ & $1 \pm 0$ & 1.0000 \\
\hline Aggression & $0.86 \pm 0.07$ & $0.95 \pm 0.05$ & 0.3538 \\
\hline Vocalization & $0.81 \pm 0.08$ & $0.85 \pm 0.08$ & 0.7927 \\
\hline Penlight vision & $0.875 \pm 0.125$ & $1 \pm 0$ & 0.2305 \\
\hline Body weight & $39.21 \pm 2.45$ & $33.56 \pm 3.35$ & 0.4272 \\
\hline
\end{tabular}

*Significant difference between the CON and $\mathrm{K} 0$ groups as analyzed by unpaired $t$ test.

selective neurons and thereby facilitate survival as adults, allowing description of the adult phenotypic changes observed in glut $3^{\text {flox } / \text { flox/CaMK2 } \alpha-\mathrm{Cre}+}$ mice.

Because CaMK $2 \alpha$-Cre-mediated deletion of target genes was previously reported to be seen in murine brains as early as in the 2.5-month-old and beyond (Chen et al., 2001; Fan et al., 2001), we undertook some studies at 5 months of age and determined the continued lack of overt phenotypic changes. Our studies then began focusing on a subsequent adult stage of $8-10$ months and determined no significant change in anthropometric measurements (body weight: $\mathrm{KO}=33.56 \pm 3.35 \mathrm{~g}[n=21]$ vs $\mathrm{CON}=$ $39.2 \pm 2.45 \mathrm{~g}[n=22]$; nose-rump length: $\mathrm{KO} 9.75 \pm 0.12 \mathrm{~cm}$ $[n=21]$ vs $\mathrm{CON}=9.81 \pm 0.11 \mathrm{~cm}[n=22])$.

We examined Glut3 mRNA in 10-month-old mouse brain sections by in situ hybridization histochemistry (Fig. 12A-K). Antisense probes against the glut3 gene evoked positive signals in 
A

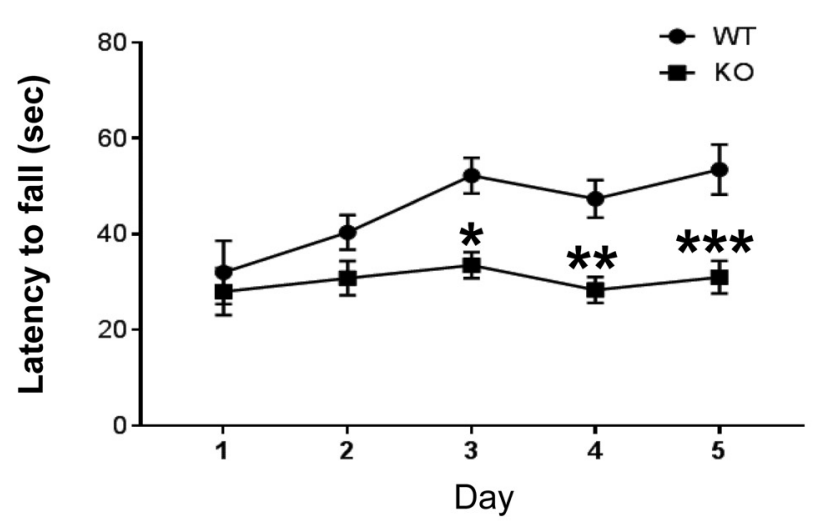

C

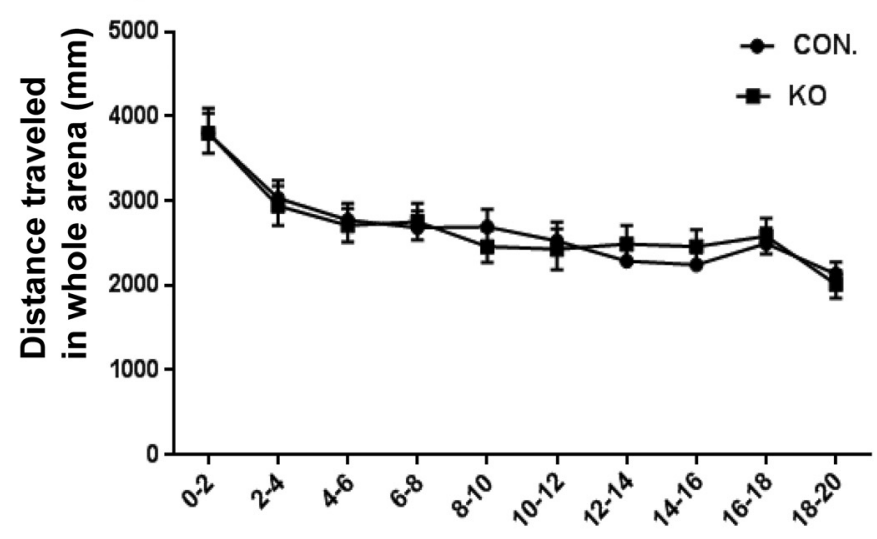

$\mathbf{E}$

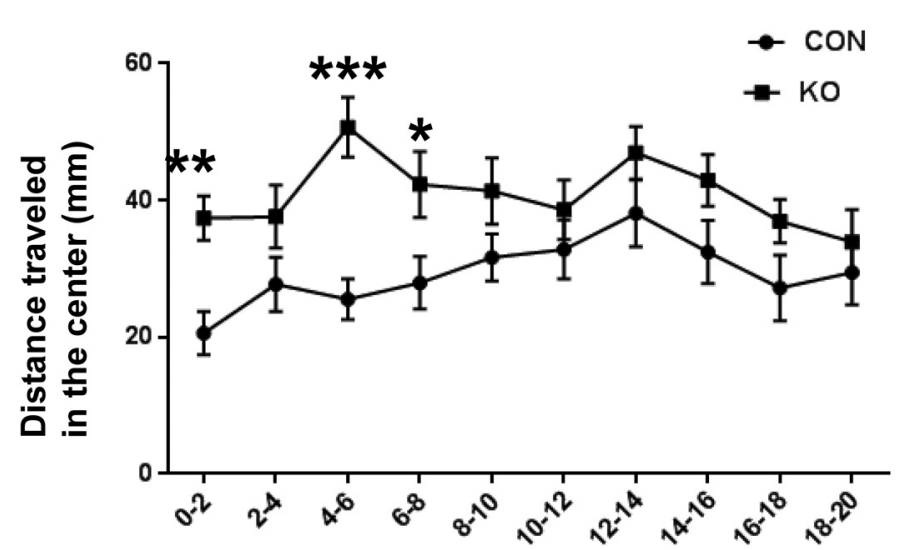

B

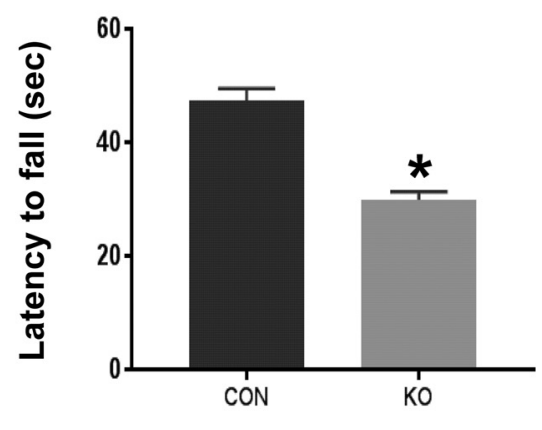

D

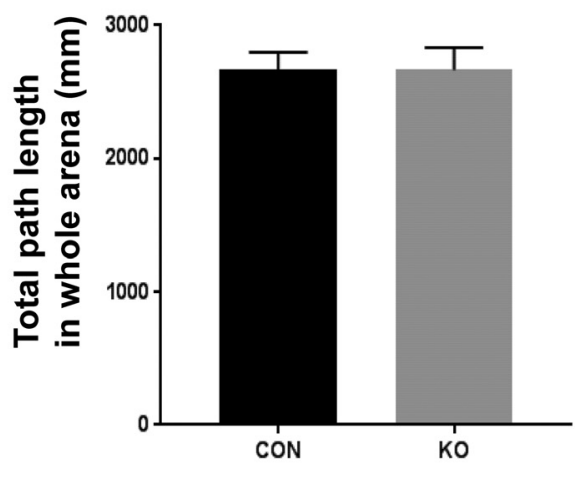

$\mathbf{F}$

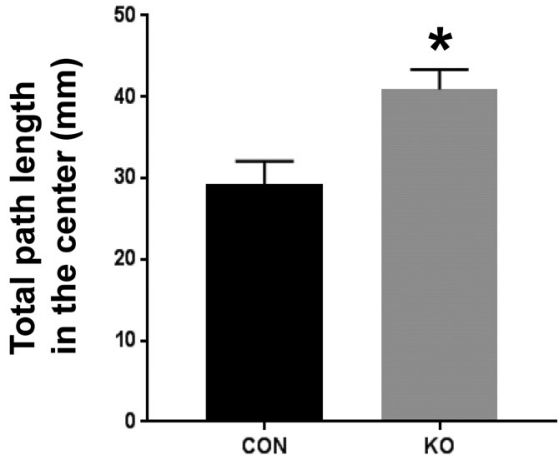

Figure 14. A, Accelerating rotarod test was performed to assess motor learning and motor coordination. K0 mice showed significant motor coordination problems and fell sooner from the rod than CON mice (two-way ANOVA followed by Sidak's multiple-comparisons test (interaction, Fstatistic [df:4, 181] $=1.416, p$-value $=0.2304$; genotype, Fstatistic [df: 1, 181] $=31.77, p$-value $<0.0001 ; * p=0.0010$ for day $3,{ }^{* *} p=0.0008$ for day $4,{ }^{* * *} p=0.0002$ for day 5. K0; $n=16$ for day $1, n=21$ for day $2-4$ and $n=20$ for day 5, CON; $n=5$ for day $1, n=22$ for day $2-4$ and $n=21$ for day 5$)$. B, Motor learning was observed in only the CON group. KO mice were significantly different from CON when comparing latency to fall from the rod at day 2-5, Mann-Whitney test (sum of ranks [11246,7090; df: 189. * $p$-value $<0.0001$, (KO: $n=99$, CON: $n=92$ mice). $\boldsymbol{C}-\boldsymbol{F}$, Open-field task. KO mice showed normal movement and activity but less anxiety compared with CON mice. $\boldsymbol{C}, \boldsymbol{D}$, Distance traveled in whole arena. Both KO and CON mice spent a similar time and traveled alike in distance within whole arena during $20 \mathrm{~min}(\mathrm{~K} 0: n=21, \mathrm{CON}: n=22$ mice, unpaired $t$ test, $t$ statistic $[$ df: 41$]=0.015, p$-value $=0.99$ in $\boldsymbol{D})$. $\boldsymbol{E}, \boldsymbol{F}$, Distance traveled in center of arena. CON mice spent less time in the center of arena and showed more tendencies in staying next to the corners, whereas glut3 K0 mice spent more time in the center (K0: $n=21$, CON: $n=22$ mice), two-way ANOVA (genotype: $F$ statistic [df: 1410] $=38.12, p$-value $<0.0001$; time spent: $F$ statistic [df: 9410] $=1.75, p$-value $=0.08$; genotype $\times$ time spent interaction: $F$ statistic [df: 9410] $=1.02$, $p$-value $=0.42$ in $E: 0-2,{ }^{* *} p=0.0046,4-6,{ }^{* * *} p<0.0001,6-8,{ }^{*} p=0.0154$; unpaired $t$ test, $t$ statistic [df: 41$]=3.124,{ }^{*} p$-value $=0.0033$ in $\left.\boldsymbol{F}\right)$.

neuronal cells of the cerebral cortex, hippocampus, and cerebellum of CON brains (Fig. $12 A, C, F, I$ ). In KO (Fig. $12 B, D, G, J$ ) brain sections, reduced transcripts in the parietal association or trunk region (asterisk) of cortex (Fig. 12B), CA1 region (aster- isks) of hippocampus (Fig. 12D) and cerebellar lobules (asterisks) (Fig. 12G,J) was evident compared with corresponding CON brains (Fig. 12 A, C, F, I). Experimental negative controls with the corresponding sense RNA probes abolished the detection of glut3 
transcripts completely (Fig. 12E, $H, K$ ), supporting the specificity of our detection system.

\section{Adult glut ${ }^{\text {flox/flox/CaMK2 } \alpha-\mathrm{Cre}+}$ (glut3 KO) mice display functional and behavioral changes}

In single-cell patch-clamp experiments from pyramidal neurons in motor cortex, a reduction in the frequency of IPSCs with no significant change in the frequency of EPSCs was evident in 10month-old glut $3 \mathrm{KO}$ versus CON (Fig. 13A-C). In addition, there was no significant change in basic membrane properties of $\mathrm{KO}$ and CON mice $\{[$ Cell membrane capacitance $(\mathrm{Pf}): \mathrm{KO}=151.6 \pm$ 15.2, $\mathrm{CON}=154 \pm 15.4$ ], [Input resistance $(\mathrm{M} \Omega): \mathrm{KO}=$ $156.8 \pm 36.1, \mathrm{CON}=127.8 \pm 30.0$,], [Time constant $(\mathrm{msec})$ : $\mathrm{KO}=4.61 \pm 0.5, \mathrm{CON}=4.67 \pm 0.39,] ; n=8$ for $\mathrm{CON}, n=10$ for $\mathrm{KO}$.

In the glut $3^{\text {flox/flox/CaMK2 } \alpha \text {-Cre+ }}$ (glut3 KO) genotype, we performed neurobehavioral testing in 8- to 10-month-old male mice to determine the impact of selective loss of Glut3 expression. Comparing glut $3 \mathrm{KO}$ mice versus their age-matched $\mathrm{CON}$ revealed reduced locomotor activity, visual placing, wire maneuver, grip strength, and body tone (Table 2) in the SHIRPA screen. To confirm these initial motor findings, we noted in the rotarod test a lower latency to fall in glut $3 \mathrm{KO}$ versus CON mice (Fig. $14 A, B$ ). The open-field test was undertaken to assess locomotor activity and the level of anxiety in these mice. The glut $3 \mathrm{KO}$ mice traveled a similar distance in the arena as the CON. However, the glut3 $\mathrm{KO}$ mice spent more time in the center rather than the periphery compared with $\mathrm{CON}$, attesting to enhanced anxiolytic behavior, perhaps due to the lack of a fear response (Fig. 14C-F). To prove this further, we performed the fear conditioning test and noted a longer time spent in the frozen state by glut3 $\mathrm{KO}$ versus $\mathrm{CON}$, supporting a longer duration in habituating to a fear response (Fig. 15A). Consistent with these results, sociability and social novelty testing revealed a lack of concern in socializing and in exploring social novelty, further supporting a lack of fear (Fig. $15 B, C)$. Morris water maze testing revealed minimal changes in glut3 $\mathrm{KO}$ versus CON (Fig. 16A-D), except for time spent in the target quadrant (Fig. 16B), suggesting impaired spatial cognition.

\section{Discussion}

This is the first report of a neural-specific glut3 homozygous knock out mouse model resulting in postnatal survival. This is because placental trophoblast glut 3 expression could be disconnected from the offspring's glut3 expression and related phenotype. Fetal brain (E18) Glut3 protein reduction $(\sim 50 \%)$ was associated with an overtly normal fetal phenotype. This gross phenotypic normalcy persisted soon after birth (P1) and during the early postnatal phase (up to PN10) despite a persistent reduction in brain glut3 expression level $(\sim 50 \%)$. These results during the early postnatal period mimicked those of the classical glut3 deletion, where the glut3-null heterozygotes expressed $50 \%$ of glut3 in the offspring (Ganguly et al., 2012). However, the classical glut3-null heterozygous fetus demonstrated a slowing of fetal growth related to a reduction in placental glut 3 expression and trans-placental glucose transport (Ganguly et al., 2007). No such change was evident in our Nestin-Cre ${ }^{+}$-mediated glut3 deletion and no intergenotype differences were noted in trans-placental glucose transport.

During the postnatal phase, a further reduction leading to an almost complete lack of brain glut3 from PN14 on occurred. It is only at this stage, where previously we have noted Glut 3 expression to peak in WT mice (Thamotharan et al., 2013), that phenotypic changes were overtly detected. Obvious stunting with a
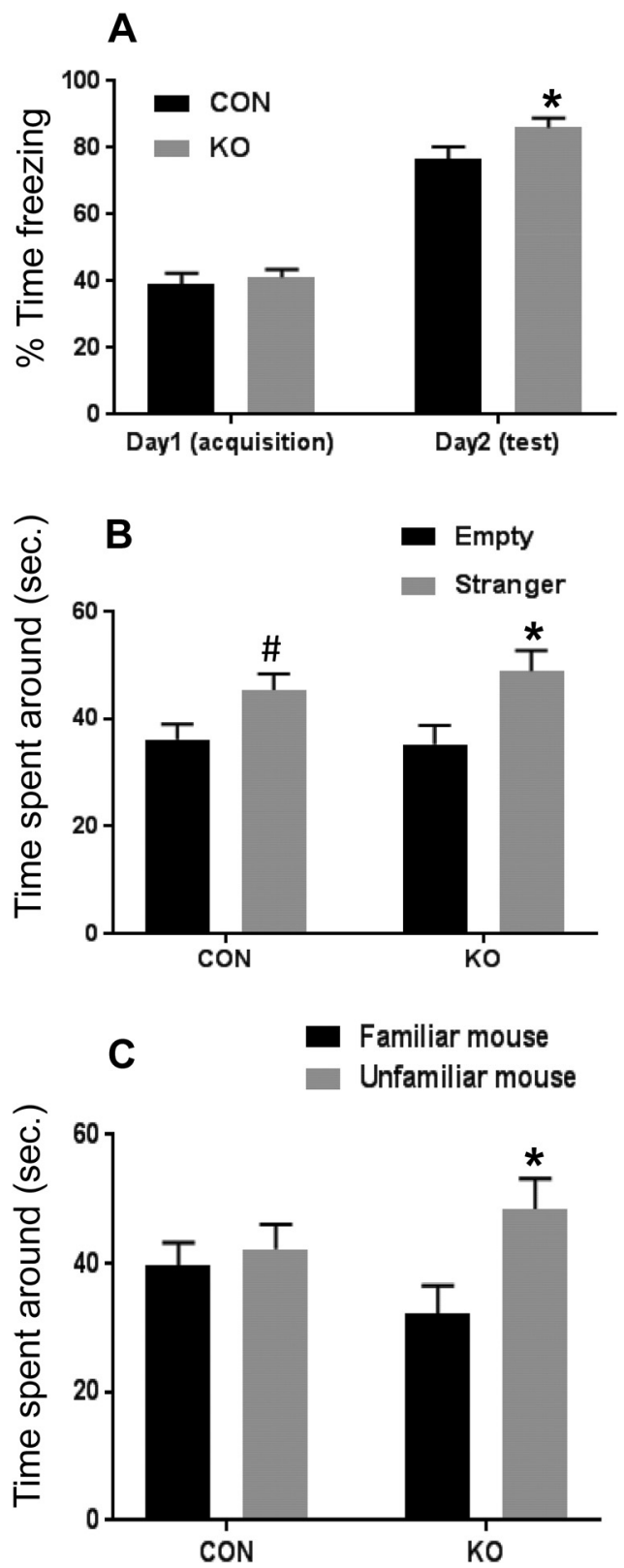

Figure 15. Contextual fear conditioning. $A$, CON mice showed impaired contextual fear conditioning. $\mathrm{KO}$ mice froze more during conditioning in the context of fear, whereas $\mathrm{CON}$ mice showed significantly lower levels of freezing (KO: $n=19$ mice, CON: $n=22$ mice, two-way ANOVA followed by Bonferroni's multiple-comparisons test: interaction, Fstatistic [df: 1,39] $=3.263, p=0.0786$; day 1 to day $2, F$ statistic [df: 1,39] $=282.9, p<0.0001$; genotype, Fstatistic [df: 1, 39] $=7.47, p=$ 0.0094 : $^{*} p$-value for day $\left.2=0.0033\right) . \boldsymbol{B}, \boldsymbol{C}$, Social interaction task. $\boldsymbol{B}$, In the sociability phase, both CON and $\mathrm{KO}$ mice spent significantly more time with novel mouse than an empty wire cup, two-way ANOVA followed by Fisher's PLSD test: interaction, Fstatistic [df: 1,82$]=0.4447, p=0.5068$; time spent around, Fstatistic [df: 1, 82] $=12.16, p=0.0008$; genotype, Fstatistic [df: 1, 82] $=0.1687$, $p=0.6823$ (K0; $n=21$ mice, ${ }^{*} p$-value $=0.0047, \mathrm{CON} ; n=22$ mice, $\# p$-value $\left.=0.047\right)$. C, At the social recognition phase, $\mathrm{CON}$ mice spent similar time with either the novel mouse or familiar mouse from the previous phase, whereas glut3 $\mathrm{KO}$ mice showed a significant trend toward the novel mouse rather than the familiar mouse, two-way ANOVA followed by Fisher's PLSD test, CON; $n=22$ mice, K0; $n=21$ mice: interaction, Fstatistic [df: 1,82] $=2.987, p=0.0877$; Time spent around, Fstatistic $[\mathrm{df}: 1,82]=5.23, p=0.0248$; genotype, Fstatistic $[\mathrm{df:} 1,82]=0.027, p=0.8699$. In the unfamiliar versus familiar of $\mathrm{KO},{ }^{*} p=0.0063$.

shortened lifespan was seen. The earliest demise was encountered at $\sim$ PN14 to the latest at $\sim$ PN31 ( $8-10 \mathrm{~d}$ postweaning), when all of the homozygotes died. This pattern does not reflect a lack of hepatic glucose production, which generally occurs very early in 


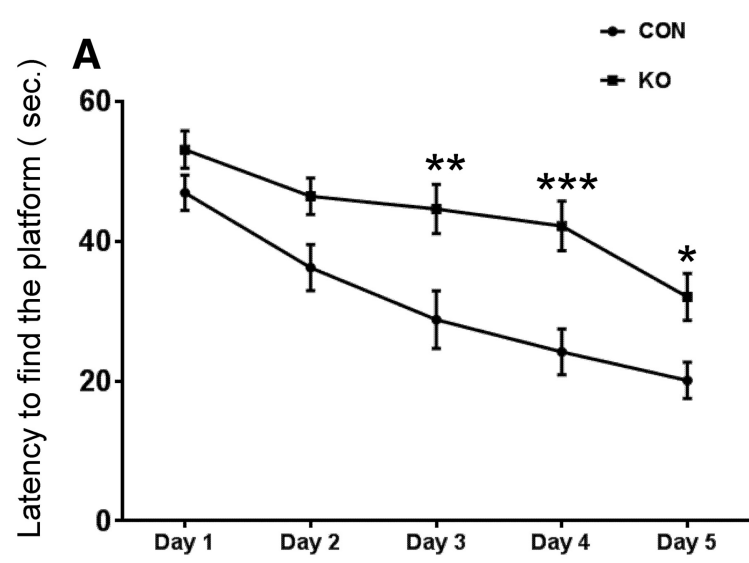

B
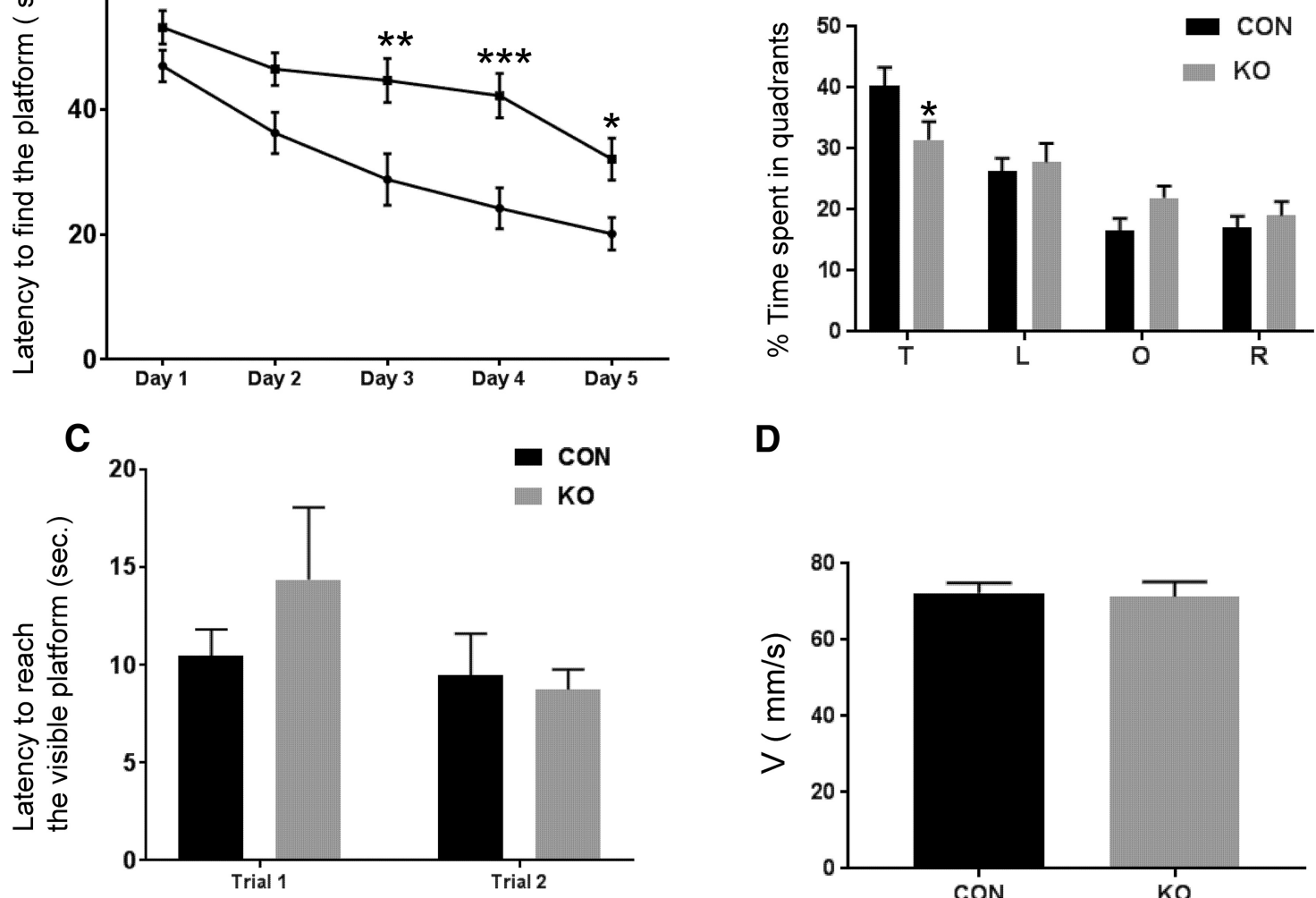

D

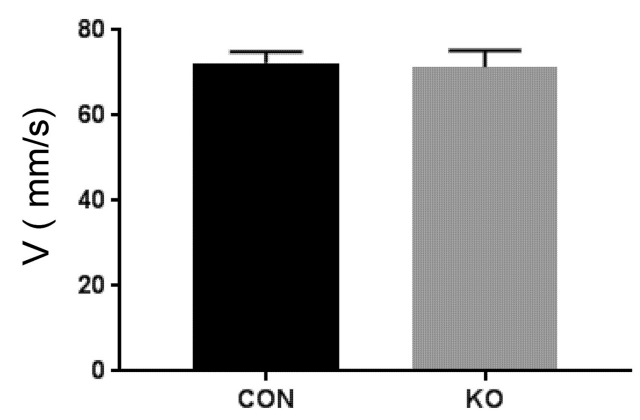

Figure 16. Morris water maze task. glut $3 \mathrm{KO}$ mice displayed impaired spatial learning. $A$, Latency to find the escape platform in five consecutive training trials. glut $3 \mathrm{KO}$ mice showed reduced learning compared with CON mice (glut3 K0; $n=20, \mathrm{CON}: n=21$ mice, two-way ANOVA followed by Bonferroni's multiple-comparisons test: interaction, $F$ statistic [df 4, 156] $=1.435, p=0.2251$; time, Fstatistic [df 4156] $=21.22, p<0.0001$; genotype, F statistic [df: 1,39] $=18.7, p=0.0001 . p$-value day 1 to $5=$ (day 1:0.8627, day 2:0.1242, ${ }^{* *}$ day 3:0.0028, ${ }^{* * *}$ day 4:0.0005, ${ }^{*}$ day $5: 0.0438$ ). $\boldsymbol{B}$, Time spent in each quadrant ( $\mathrm{T}$, target quadrant; $\mathrm{L}$, left quadrant; 0 , opposite quadrant; $\mathrm{R}$, right quadrant) was measured in the probe trial in which the platform was removed from the pool. CON mice spent more time in target quadrant than glut3 $\mathrm{KO}$ (two-way ANOVA followed by Bonferroni's multiple-comparisons test; interaction, $F$ statistic [df: 3,117$]=2.455, p=0.0666$; time spent around, $F$ statistic [df: 3,117$]=17.86, p<0.0001$; genotype, $F$ statistic [df: 1,39$]=0.0005, p=0.9821$., ${ }^{*} p$-value for target quadrant $\left.=0.0493\right) . C$, Latency to find the visible platform in glut3 $\mathrm{KO}$ mice was similar to CON mice in both trials (two-way ANOVA followed by Bonferroni's multiple-comparisons test; interaction, $F$ statistic [df: 1, 39] $=1.989, p=0.1664 ;$ time, $F$ statistic [df: 1,39] $=4.027, p=0.0518$; genotype, Fstatistic [df: 1,39] $=0.3203, p=0.5746 ; p=0.4625$ for trial 1, $p>0.9999$ for trial 2.) $\boldsymbol{D}$, No difference was observed in swim speed (unpaired $t$ test, t statistic [df: 33.46$]=0.1901, p$-value $=0.85$ ).

life. In addition, no significant change in blood glucose emerged until PN15-PN21, thereby reflecting enhanced utilization mediating the shortened lifespan.

Postnatal stunting as displayed by the glut $3 \mathrm{KO}$ mice is seen in humans related to food insecurity (Branca and Ferrari, 2002; Prendergast and Humphrey, 2014). Similarly, neurologically affected children are also known to be stunted due to compromised feeding abilities (Kerac et al., 2014). Therefore, the next concern was whether the KO mice endured a disrupted glut3-related neurological control of feeding causing postnatal growth restriction with early death. However, the KO mice demonstrated no such difficulty in feeding; rather, the milk intake was increased at PN15, perhaps in compensation for increased energy utilization or expenditure. Previously in postnatal growth-restricted rats/mice, an increase in oxygen consumption and energy expenditure was reported (Dai et al., 2012; Shin et al., 2012). However, at PN21, milk contents in the stomach were completely absent in $\mathrm{KO}$ but present in $\mathrm{CON}$ mice, perhaps heralding decompensation.

The observed phenotype is not solely due to a change in diet from high ketogenic maternal milk to high carbohydrate mouse chow. This is because some of these $\mathrm{KO}$ mice died while still on maternal milk and those that survived weaning lasted for nearly a week to 10 days on a high carbohydrate diet. In fact, early introduction of a ketogenic diet in a small subset, although mildly improving their body weight gain at PN15, failed to rescue by prolonging their lifespan. Given the extreme stunting of the glut3 $\mathrm{KO}$ mice, it proved impossible to undertake additional blood or CSF testing to determine the cause of stunting or shortened lifespan. It is possible that neural regulation of critically essential hormonal output or nonglucose metabolomic homeostasis may have been compromised, adversely affecting somatic growth and lifespan.

We next focused on brain Glut3 expression and observed that Glut3 is noted as early as E13.5 (or even earlier), with a reduction in expressed amounts seen at $\mathrm{E} 18$ due to the presence of Nestin in the same neural cell types. However, it was not until PN15, a time when Glut3 expression peaks normally (Khan et al., 1999; Thamotharan et al., 2013), that an almost complete lack of Glut3 emerged. It is also at this developmental time point that obvious stunting was exhibited. In addition, consistent with the reduction in brain weights, a reduction in cerebral cortical thickness was observed, reflecting postnatal microcephaly. We therefore focused on the PN15 brain to determine whether there was any disruption of neurons or dendrites in particular and noted only a trend toward a decrease in synaptophysin, Map2, or tubulin be- 
tween the two genotypes, with a reduction in dendritic spines of pyramidal neurons. Similarly, no compensation was evident by other related glucose transporter isoforms with, again, only a trend toward an increase seen with neuronal MCT2. This suggestive increase in neuronal MCT2 supports the recruitment of ketones to fuel the energy metabolism in the absence of Glut3mediated glucose supply. Conversely, the absence of a more robust increase in neuronal MCT2 when Glut3 is absent may relate to a dilution effect by the multiple non-MCT2-expressing brain cellular elements. Also, in contrast to Glut3, which peaks at PN15, MCT2 achieves peak expression at only 2 months of age (Zhao et al., 2010), with concentrations being relatively low at PN15.

Using ${ }^{18} \mathrm{~F}$-deoxy-glucose PET scanning, reduced or lack of Glut3-mediated neuronal glucose uptake was not detected. This is because the other isoforms, particularly Glut1, which is uniformly expressed by the endothelial cells of microvasculature, continues to transport glucose from the circulation into the brain interstitial space and glial cells. Previously, in vitro studies using cultured rat cerebellar granule neurons demonstrated a key role for the membrane-bound Glut3 regulated by activated AMPK (ATP: AMP ratio). This was mediating hyperpolarization of the mitochondrial membrane potential associated with transient glutamate excitation, thereby potently sensitizing neurons to excitotoxicity. Therefore, Glut3 was critical in mediating neuronal tolerance to excitotoxicity (Weisová et al., 2009). Confirmation of such a functional effect in vivo due to a lack of Glut3 in cortical neurons was forthcoming with patch-clamp investigations. Here, in the glut3 KO genotype, an increased frequency of paroxysmal events and a reduced latency period to the first paroxysmal discharge when $\mathrm{GABA}_{\mathrm{A}}$ receptors were blocked were evident. Increased excitability could partially explain the loss of dendritic spines observed in pyramidal neurons, possibly as a compensatory mechanism to prevent neuronal damage. Our neurobehavioral assessments at this early age revealed a significant reduction in vocalizations at PN14, being normal earlier at PN7, consistent with the other phenotypic changes in $\mathrm{KO}$ versus CON. In adults, conditional deletion of glut 3 led to motor and social deficits. Both conditional models displayed behaviors typical of autism spectrum disorders.

We next focused on the retina as a simpler tissue that serves as a window into the CNS. The retinal inner plexus layer demonstrated a lack of Glut3 expression, along with structural disruption of the plexiform layer. Further, a reduction in Glut3 expression in spermatids was noted, suggesting colocalization of Nestin and Glut3. This reduced Glut3 expression in spermatids could compromise reproduction if these mice had survived until sexual maturation. In addition to the brain, followed next by testes, Glut3 expression is very low in other PN15 tissues and therefore cannot be responsible for the postnatal stunting of Glut3 KO mice.

Due to the short lifespan encountered when global neural glut3 deletion was accomplished, it became imperative next to undertake selective neuronal glut3 deletion to facilitate survival as an adult. To this end, the CaMK $2 \alpha$-mediated glut 3 deletion was accomplished. CaMK2 $\alpha$, although not expressed in placenta, is expressed in specific regions of the adult cerebral cortex, hippocampus, thalamus, hypothalamus, and amygdala. Therefore, the expected result is abolition of glut 3 gene expression in these selective brain regions. This abolition occurred as early as 5 months of age and lasted until 10 months of age and beyond, the deletion being more complete with advancing age. Whereas no gross impairment was evident, single-cell patch-clamp record- ings of cortical neurons revealed reduced iPSCs, supporting increased excitability. Interestingly, in mouse models of autism, a loss of fast-spiking, parvalbumin-expressing interneurons has been observed (Ferguson and Gao, 2018).

More importantly, this mouse line allowed us to examine adult neurobehavior in the context of previously reported classical glut3-null heterozygous mouse (Zhao et al., 2010; Dai et al., 2017) results. Although the classical mouse model consisted of global neuronal reduction in Glut3 expression by $\sim 50 \%$ (Ganguly et al., 2012), our present conditional mouse model revealed near absence of Glut3 expression in select neurons. This distinction is important in interpreting our present observations. Previously, we reported a lack of change in the rotarod (motor abilities), open field (anxiety), and fear conditioning in the glut3null heterozygotes (Zhao et al., 2010); however, in our present conditional glut $3 \mathrm{KO}$ model, we observed reduced motor abilities and anxiolytic behaviors with a lack of fear for space exploration or social interaction with strangers. These changes perhaps reflect perturbed neuronal function of the limbic system and cerebral cortex. Previous studies using $\mathrm{CaMK} 2 \alpha-\mathrm{Cre}^{+}$transgenic mice deleting corticotrophin-releasing hormone receptor 1 also led to anxiolytic changes similar to our present observations, suggesting dysfunction of similar neuronal pathways (Müller et al., 2003). Further, when the oxytocin receptor was deleted under the regulation of CaMK $2 \alpha$ promoter, changes in sociability emerged (Lee et al., 2008). When spatial memory was examined by the Morris water maze test, the classical glut3-null heterozygotes revealed significant disruption, whereas our present conditional mouse model displayed a finer disruption, again attesting to differences between the two deletions. Most importantly, the limbic system is the reward-generating system, which can be disrupted by methamphetamines and cocaine (Adinoff, 2004; Koob and Volkow, 2010; Berridge and Kringelbach, 2015). Whether the disruption of Glut3-mediated energy supply to these particular neurons affects these pathways toward blunting the effect of such drugs needs future investigation.

In conclusion, the phenotype (global neural deletion) during the postnatal phase consisted of stunting, microcephaly, reduced vocalizations, and shortened lifespan, whereas survival into adulthood (select neuronal deletion) led to perturbed neurobehavioral responses that spell danger for the subject carrying the glut3 deletion. Our studies provide the neural basis for some of the observed associations tying glut $3 \mathrm{CNV}$ s with age-specific presentations of certain neurodevelopmental disorders.

\section{References}

Adinoff B (2004) Neurobiologic processes in drug reward and addiction. Harv Rev Psychiatry 12:305-320. CrossRef Medline

Agostini M, Romeo F, Inoue S, Niklison-Chirou MV, Elia AJ, Dinsdale D, Morone N, Knight RA, Mak TW, Melino G (2016) Metabolic reprogramming during neuronal differentiation. Cell Death Differ 23:15021514. CrossRef Medline

Alves MG, Martins AD, Vaz CV, Correia S, Moreira PI, Oliveira PF, Socorro $S$ (2014) Metformin and male reproduction: effects on sertoli cell metabolism. Br J Pharmacol 171:1033-1042. CrossRef Medline

Barron CC, Bilan PJ, Tsakiridis T, Tsiani E (2016) Facilitative glucose transporters: implications for cancer detection, prognosis and treatment. Metabolism 65:124-139. CrossRef Medline

Berridge KC, Kringelbach ML (2015) Pleasure systems in the brain. Neuron 86:646-664. CrossRef Medline

Branca F, Ferrari M (2002) Impact of micronutrient deficiencies on growth: the stunting syndrome. Ann Nutr Metab 46:8-17. CrossRef Medline

Bruckner BA, Ammini CV, Otal MP, Raizada MK, Stacpoole PW (1999) Regulation of brain glucose transporters by glucose and oxygen deprivation. Metabolism 48:422-431. CrossRef Medline

Carayannopoulos MO, Xiong F, Jensen P, Rios-Galdamez Y, Huang H, Lin S, 
Devaskar SU (2014) GLUT3 gene expression is critical for embryonic growth, brain development and survival. Mol Genet Metab 111:477-483. CrossRef Medline

Chen RZ, Akbarian S, Tudor M, Jaenisch R (2001) Deficiency of methyl$\mathrm{CpG}$ binding protein-2 in CNS neurons results in a rett-like phenotype in mice. Nat Genet 27:327-331. CrossRef Medline

Connealy BD, Northrup H, Au KS (2014) Genetic variations in the GLUT3 gene associated with myelomeningocele. Am J Obstet Gynecol 211: 305.e1-8. Medline

Cummings DM, André VM, Uzgil BO, Gee SM, Fisher YE, Cepeda C, Levine MS (2009) Alterations in cortical excitation and inhibition in genetic mouse models of Huntington's disease. J Neurosci 29:10371-10386. CrossRef Medline

Dai Y, Thamotharan S, Garg M, Shin BC, Devaskar SU (2012) Superimposition of postnatal calorie restriction protects the aging male intrauterine growth-restricted offspring from metabolic maladaptations. Endocrinology 153:4216-4226. CrossRef Medline

Dai Y, Zhao Y, Tomi M, Shin BC, Thamotharan S, Mazarati A, Sankar R, Wang EA, Cepeda C, Levine MS, Zhang J, Frew A, Alger JR, Clark PM, Sondhi M, Kositamongkol S, Leibovitch L, Devaskar SU (2017) Sexspecific life course changes in the neuro-metabolic phenotype of Glut3 null heterozygous mice: ketogenic diet ameliorates electroencephalographic seizures and improves sociability. Endocrinology 158:936-949. CrossRef Medline

Devaskar S, Chundu K, Zahm DS, Holtzclaw L, Holloran K (1992) The neonatal rabbit brain glucose transporter. Brain Res Dev Brain Res 67:95103. CrossRef Medline

Dworschak GC, Draaken M, Hilger AC, Schramm C, Bartels E, Schmiedeke E, Grasshoff-Derr S, Märzheuser S, Holland-Cunz S, Lacher M, Jenetzky E, Zwink N, Schmidt D, Nöthen MM, Ludwig M, Reutter H (2015) Genome-wide mapping of copy number variations in patients with both anorectal malformations and central nervous system abnormalities. Birth Defects Res A Clin Mol Teratol 103:235-242. CrossRef Medline

Fan G, Beard C, Chen RZ, Csankovszki G, Sun Y, Siniaia M, Biniszkiewicz D, Bates B, Lee PP, Kuhn R, Trumpp A, Poon C, Wilson CB, Jaenisch R (2001) DNA hypomethylation perturbs the function and survival of CNS neurons in postnatal animals. J Neurosci 21:788-797. CrossRef Medline

Ferguson BR, Gao WJ (2018) PV interneurons: critical regulators of E/I balance for prefrontal cortex-dependent behavior and psychiatric disorders. Front Neural Circuits 12:37. CrossRef Medline

Flavahan WA, Wu Q, Hitomi M, Rahim N, Kim Y, Sloan AE, Weil RJ, Nakano I, Sarkaria JN, Stringer BW, Day BW, Li M, Lathia JD, Rich JN, Hjelmeland $A B$ (2013) Brain tumor initiating cells adapt to restricted nutrition through preferential glucose uptake. Nat Neurosci 16:1373-1382. CrossRef Medline

Fukushima N, Yokouchi K, Kawagishi K, Moriizumi T (2006) Effect of maternal deprivation on milk intake in normal and bilaterally facial nerveinjured developing rats. Neurosci Res 54:154-157. CrossRef Medline

Fung C, Evans E, Shin D, Shin BC, Zhao Y, Sankar R, Chaudhuri G, Devaskar SU (2010) Hypoxic-ischemic brain injury exacerbates neuronal apoptosis and precipitates spontaneous seizures in glucose transporter isoform 3 heterozygous null mice. J Neurosci Res 88:3386-3398. CrossRef Medline

Galardo MN, Riera MF, Pellizzari EH, Chemes HE, Venara MC, Cigorraga SB, Meroni SB (2008) Regulation of expression of sertoli cell glucose transporters 1 and 3 by FSH, IL1 beta, and bFGF at two different timepoints in pubertal development. Cell Tissue Res 334:295-304. CrossRef Medline

Ganguly A, McKnight RA, Raychaudhuri S, Shin BC, Ma Z, Moley K, Devaskar SU (2007) Glucose transporter isoform-3 mutations cause early pregnancy loss and fetal growth restriction. Am J Physiol Endocrinol Metab 292:E1241-E1255. CrossRef Medline

Ganguly A, Collis L, Devaskar SU (2012) Placental glucose and amino acid transport in calorie-restricted WT and Glut3 null heterozygous mice. Endocrinology 153:3995-4007. CrossRef Medline

Gibson LC, Shin BC, Dai Y, Freije W, Kositamongkol S, Cho J, Devaskar SU (2015) Early leptin intervention reverses perturbed energy balance regulating hypothalamic neuropeptides in the pre- and postnatal calorierestricted female rat offspring. J Neurosci Res 93:902-912. CrossRef Medline

Gould GW, Holman GD (1993) The glucose transporter family: structure, function and tissue-specific expression. Biochem J 295:329-341. CrossRef Medline
Kerac M, Postels DG, Mallewa M, Alusine Jalloh A, Voskuijl WP, Groce N, Gladstone M, Molyneux E (2014) The interaction of malnutrition and neurologic disability in africa. Semin Pediatr Neurol 21:42-49. CrossRef Medline

Khan JY, Rajakumar RA, McKnight RA, Devaskar UP, Devaskar SU (1999) Developmental regulation of genes mediating murine brain glucose uptake. Am J Physiol 276:R892-R900. Medline

Koob GF, Volkow ND (2010) Neurocircuitry of addiction. Neuropsychopharmacology 35:217-238. CrossRef Medline

Lee HJ, Caldwell HK, Macbeth AH, Tolu SG, Young WS 3rd (2008) A conditional knockout mouse line of the oxytocin receptor. Endocrinology 149:3256-3263. CrossRef Medline

Lesch KP, Selch S, Renner TJ, Jacob C, Nguyen TT, Hahn T, Romanos M, Walitza S, Shoichet S, Dempfle A, Heine M, Boreatti-Hümmer A, Romanos J, Gross-Lesch S, Zerlaut H, Wultsch T, Heinzel S, Fassnacht M, Fallgatter A, Allolio B, et al. (2011) Genome-wide copy number variation analysis in attention-deficit/hyperactivity disorder: association with neuropeptide Y gene dosage in an extended pedigree. Mol Psychiatry 16:491-503. CrossRef Medline

Loening AM, Gambhir SS (2003) AMIDE: a free software tool for multimodality medical image analysis. Mol Imaging 2:131-137. CrossRef Medline

Masin M, Vazquez J, Rossi S, Groeneveld S, Samson N, Schwalie PC, Deplancke B, Frawley LE, Gouttenoire J, Moradpour D, Oliver TG, Meylan E (2014) GLUT3 is induced during epithelial-mesenchymal transition and promotes tumor cell proliferation in non-small cell lung cancer. Cancer Metab 2:11. CrossRef Medline

Massari F, Ciccarese C, Santoni M, Iacovelli R, Mazzucchelli R, Piva F, Scarpelli M, Berardi R, Tortora G, Lopez-Beltran A, Cheng L, Montironi R (2016) Metabolic phenotype of bladder cancer. Cancer Treat Rev 45:4657. CrossRef Medline

Merker S, Reif A, Ziegler GC, Weber H, Mayer U, Ehlis AC, Conzelmann A, Johansson S, Müller-Reible C, Nanda, Haaf T, Ullmann R, Romanos M, Fallgatter AJ, Pauli P, Strekalova T, Jansch C, Vasquez AA, Haavik J, Ribasés M, et al. (2017) SLC2A3 single-nucleotide polymorphism and duplication influence cognitive processing and population-specific risk for attention-deficit/hyperactivity disorder. J Child Psychol Psychiatry 58:798-809. CrossRef Medline

Mitra R, Jadhav S, McEwen BS, Vyas A, Chattarji S (2005) Stress duration modulates the spatiotemporal patterns of spine formation in the basolateral amygdala. Proc Natl Acad Sci U S A 102:9371-9376. CrossRef Medline

Müller MB, Zimmermann S, Sillaber I, Hagemeyer TP, Deussing JM, Timpl P, Kormann MS, Droste SK, Kühn R, Reul JM, Holsboer F, Wurst W (2003) Limbic corticotropin-releasing hormone receptor 1 mediates anxiety-related behavior and hormonal adaptation to stress. Nat Neurosci 6:1100-1107. CrossRef Medline

Nagamatsu S, Kornhauser JM, Burant CF, Seino S, Mayo KE, Bell GI (1992) Glucose transporter expression in brain. cDNA sequence of mouse GLUT3, the brain facilitative glucose transporter isoform, and identification of sites of expression by in situ hybridization. J Biol Chem 267:467472. Medline

Nagy A, Vintersten K, Gertsenstein M, Behringer R (2003) Manipulating the mouse embryo: a laboratory manual. Cold Spring Harbor, NY: Cold Spring Harbor Laboratory.

Ogino H, Hisanaga A, Kohno T, Kondo Y, Okumura K, Kamei T, Sato T, Asahara H, Tsuiji H, Fukata M, Hattori M (2017) Secreted metalloproteinase ADAMTS-3 inactivates reelin. J Neurosci 37:3181-3191. CrossRef Medline

Onodera Y, Nam JM, Bissell MJ (2014) Increased sugar uptake promotes oncogenesis via EPAC/RAP1 and O-GlcNAc pathways. J Clin Invest 124: 367-384. CrossRef Medline

Poeggel G, Helmeke C, Abraham A, Schwabe T, Friedrich P, Braun K (2003) Juvenile emotional experience alters synaptic composition in the rodent cortex, hippocampus, and lateral amygdala. Proc Natl Acad Sci U S A 100:16137-16142. CrossRef Medline

Prendergast AJ, Humphrey JH (2014) The stunting syndrome in developing countries. Paediatr Int Child Health 34:250-265. CrossRef Medline

Roeske D, Ludwig KU, Neuhoff N, Becker J, Bartling J, Bruder J, Brockschmidt FF, Warnke A, Remschmidt H, Hoffmann P, Müller-Myhsok B, Nöthen MM, Schulte-Körne G (2011) First genome-wide association scan on neurophysiological endophenotypes points to trans-regulation 
effects on SLC2A3 in dyslexic children. Mol Psychiatry 16:97-107. CrossRef Medline

Roy S, Watkins N, Heck D (2012) Comprehensive analysis of ultrasonic vocalizations in a mouse model of fragile $\mathrm{X}$ syndrome reveals limited, call type specific deficits. PLoS One 7:e44816. CrossRef Medline

Schmidt S, Hommel A, Gawlik V, Augustin R, Junicke N, Florian S, Richter M, Walther DJ, Montag D, Joost HG, Schürmann A (2009) Essential role of glucose transporter GLUT3 for post-implantation embryonic development. J Endocrinol 200:23-33. CrossRef Medline

Shah K, Desilva S, Abbruscato T (2012) The role of glucose transporters in brain disease: diabetes and Alzheimer's disease. Int J Mol Sci 13:1262912655. CrossRef Medline

Shin BC, Fujikura K, Suzuki T, Tanaka S, Takata K (1997) Glucose transporter GLUT3 in the rat placental barrier: a possible machinery for the transplacental transfer of glucose. Endocrinology 138:3997-4004. CrossRef Medline

Shin BC, Suzuki M, Inukai K, Anai M, Asano T, Takata K (1998) Multiple isoforms of the regulatory subunit for phosphatidylinositol 3-kinase (PI3kinase) are expressed in neurons in the rat brain. Biochem Biophys Res Commun 246:313-319. CrossRef Medline

Shin BC, McKnight RA, Devaskar SU (2004) Glucose transporter GLUT8 translocation in neurons is not insulin responsive. J Neurosci Res 75:835844. CrossRef Medline

Shin BC, Dai Y, Thamotharan M, Gibson LC, Devaskar SU (2012) Pre- and postnatal calorie restriction perturbs early hypothalamic neuropeptide and energy balance. J Neurosci Res 90:1169-1182. CrossRef Medline

Skeide MA, Kirsten H, Kraft I, Schaadt G, Müller B, Neef N, Brauer J, Wilcke A, Emmrich F, Boltze J, Friederici AD (2015) Genetic dyslexia risk variant is related to neural connectivity patterns underlying phonological awareness in children. Neuroimage 118:414-421. CrossRef Medline

Szablewski L (2017) Glucose transporters in brain: in health and in Alzheimer's disease. J Alzheimers Dis 55:1307-1320. CrossRef Medline

Taschereau R, Vu NT, Chatziloannou AF (2014) Calibration and data standardization of a prototype bench-top preclinical CT. In: 2014 IEEE Nuclear Science Symposium and Medical Imaging Conference (NSS/MIC), pp 1-2, Seattle, WA: IEEE. Available at http//ieeexplore.ieee.org/document/ $7430845 /$.
Thamotharan S, Stout D, Shin BC, Devaskar SU (2013) Temporal and spatial distribution of murine placental and brain GLUT3-luciferase transgene as a readout of in vivo transcription. Am J Physiol Endocrinol Metab 304:E254-E266. CrossRef Medline

Tsien JZ, Chen DF, Gerber D, Tom C, Mercer EH, Anderson DJ, Mayford M, Kandel ER, Tonegawa S (1996) Subregion- and cell type-restricted gene knockout in mouse brain. Cell 87:1317-1326. CrossRef Medline

Veal CD, Reekie KE, Lorentzen JC, Gregersen PK, Padyukov L, Brookes AJ (2014) A 129-kb deletion on chromosome 12 confers substantial protection against rheumatoid arthritis, implicating the gene SLC2A3. Hum Mutat 35:248-256. CrossRef Medline

Vittori A, Breda C, Repici M, Orth M, Roos RA, Outeiro TF, Giorgini F, Hollox EJ, Hollox EJ (2014) Copy-number variation of the neuronal glucose transporter gene SLC2A3 and age of onset in Huntington's disease. Hum Mol Genet 23:3129-3137. CrossRef Medline

Weisová P, Concannon CG, Devocelle M, Prehn JH, Ward MW (2009) Regulation of glucose transporter 3 surface expression by the AMP-activated protein kinase mediates tolerance to glutamate excitation in neurons. J Neurosci 29:2997-3008. CrossRef Medline

Wöhr M, Roullet FI, Crawley JN (2011) Reduced scent marking and ultrasonic vocalizations in the BTBR $\mathrm{T}+\mathrm{tf} / \mathrm{J}$ mouse model of autism. Genes Brain Behav 10:35-43. CrossRef Medline

Yu S, Zhao T, Guo M, Fang H, Ma J, Ding A, Wang F, Chan P, Fan M (2008) Hypoxic preconditioning up-regulates glucose transport activity and glucose transporter (GLUT1 and GLUT3) gene expression after acute anoxic exposure in the cultured rat hippocampal neurons and astrocytes. Brain Res 1211:22-29. CrossRef Medline

Zhao Y, Fung C, Shin D, Shin BC, Thamotharan S, Sankar R, Ehninger D, Silva A, Devaskar SU (2010) Neuronal glucose transporter isoform 3 deficient mice demonstrate features of autism spectrum disorders. Mol Psychiatry 15:286-299. CrossRef Medline

Zovein A, Flowers-Ziegler J, Thamotharan S, Shin D, Sankar R, Nguyen K, Gambhir S, Devaskar SU (2004) Postnatal hypoxic-ischemic brain injury alters mechanisms mediating neuronal glucose transport. Am J Physiol Regul Integr Comp Physiol 286:R273-R282. CrossRef Medline 